\title{
Morfología y evolución glaciar en el Macizo del Cornión (Picos de Europa, Montañas Cantábricas)
}

\section{Glacial morphology and evolution in the Cornión Massif (Picos de Europa, Cantabrian Mountains)}

\author{
RUIZ-FERNÁNDEZ, J. ${ }^{1}$, GARCÍA-HERNÁNDEZ, C. ${ }^{1}$ \\ 'Departamento de Geografía, Universidad de Oviedo.ruizjesus@uniovi.es
}

https://doi.org/10.17979/cadlaxe.2018.40.0.4912

enviado 20/4/2018 aceptado 12/12/2018

\section{Resumen:}

En este artículo se analizan la morfología y las fases glaciares reconocibles en el Macizo Occidental de los Picos de Europa, a partir de los depósitos y formas erosivas conservadas, de las relaciones morfoestratigráficas entre dichas evidencias, así como de la realización de dataciones absolutas de C14 en secuencias sedimentarias asociadas. Los resultados del mismo son la identificación de cuatro fases glaciares principales desde la Última Glaciación: Fase de Máxima Extensión del Hielo (MEH, con ocho glaciares), Fase Interna (con ocho glaciares), Fase Glaciar de Altitud (Tardiglaciar, con 37 glaciares) y Fase de glaciares de fondo de circo (Pequeña Edad del Hielo, con tres glaciares). La superficie glaciada en cada una de ellas fue de 7.329,8, 5.842,9, 797,4 y 10 ha respectivamente. Para las dos primeras se han obtenido edades mínimas de $36.718 \pm 1.203$ y $11.150 \pm 900$ años cal BP. Se confirma nuevamente la antecedencia en la MEH dentro de la Última Glaciación de los glaciares generados en las Montañas Cantábricas con respecto al Último Máximo Glaciar Global. 
Palabras clave: Formas y depósitos glaciares, reconstrucción glaciar, fases glaciares, Último Máximo Glaciar Global, asincronía, Montañas Cantábricas.

\begin{abstract}
This paper examines the glacial morphology and glacial stages of the Western Massif of the Picos de Europa, through the study of the preserved deposits and erosive landforms, the morphostratigraphic relationships between these evidences, as well as $14 \mathrm{C}$ datings in related sedimentary sequences. The main results are the identification of four main glacial stages since the Last Glaciation: Maximum Glacial Advance (eight glaciers), Glacial Expansion after the Maximum Advance (eight glaciers), Late Glacial (37 glaciers) and Little Ice Age (three glaciers). The glaciated surface in each of them was 7,329.8, 5,842.9, 797.4 and 10 ha, respectively. For the first two glacial stages, minimum ages of $36,718 \pm 1,203$ and $11,150 \pm 900$ years BP were obtained. As in previous studies, the asynchronicity between the Maximum Ice Extent within the Last Glaciation of the Cantabrian glaciers with respect to the global Last Glacial Maximum is confirmed.
\end{abstract}

Key words: Glacial landforms and deposits, glacial reconstruction, glacial stages, Global Last Glacial Maximum, asynchronicity, Cantabrian Mountains. 


\section{INTRODUCCIÓN}

Si bien existen aportaciones anteriores de notable interés (véase al respecto RodríguezRodríguez et al., 2015), se puede afirmar que el avance decisivo en el conocimiento sobre las huellas glaciares que se conservan en las Montañas Cantábricas arranca a partir de la década de 1970. Desde entonces, el debate científico ha focalizado su atención en la existencia o no de vestigios de una o varias glaciaciones, en las fases glaciares reconocibles dentro de la más reciente, en la reconstrucción de los diferentes glaciares durante la máxima extensión de los hielos (MEH) dentro de la Última Glaciación, en la altitud de los frentes, así como en la existencia o no de glaciarismo en conjuntos montañosos de altitud moderada (Martínez de Pisón y Arenillas, 1979; Frochoso, 1980 y 1990; Frochoso y Castañón, 1986 y 1998; Castañón, 1989, 1990; Flor y Bailón-Misioné, 1989; Gale y Hoare, 1997; García de Celis, 1997; González-Gutiérrez, 2002; GonzálezTrueba, 2005, 2007a; González Trueba et al., 2008; Santos, 2010; Santos et al., 2013).

Por su parte, la reciente generalización de las técnicas de datación ha permitido crear un marco cronológico cada vez más preciso. En este sentido, y al igual que ocurre en otros ámbitos montañosos de la Península Ibérica como los Pirineos o Sierra Nevada, diversos estudios han propuesto un máximo avance glaciar anterior al Último Máximo Glaciar Global (UMGG), en un rango cronológico de 45-36 ka (Jiménez y Farias, 2002; Moreno et al., 2010; Serrano et al., 2012, 2013; Jiménez et al., 2013; Pellitero, 2013; Rodríguez-Rodríguez et al., 2015; Ruiz-Fernández et al., 2016b), alimentando un intenso e interesante debate científico sobre la asincronía de los glaciares del Sur de
Europa/Cuenca Mediterránea con respecto al UMGG, cuando, en cambio, alcanza su máxima extensión el inlandsis escandinavo (Hughes et al., 2006; Hughes y Woodward, 2008; García-Ruiz et al., 2010). No obstante, en los últimos años comienzan a ser publicados algunos trabajos en los que se han obtenido cronologías muy anteriores al rango citado (Frochoso et al., 2013; RodríguezRodríguez et al., 2016), evidenciado la existencia de fases glaciares más antiguas que las previamente detectadas.

Pese a ello, aún quedan importantes interrogantes por resolver en cuanto a la extensión del glaciarismo en numerosos sectores de la Cordillera Cantábrica (incluidos los Picos de Europa y su entorno), las fases glaciares reconocibles, así como en lo referente a la evolución ambiental postglaciar. En este sentido, los objetivos del presente estudio son: i) detallar la morfología glaciar de uno de los principales macizos que integran la alta montaña cantábrica (el Macizo Occidental de los Picos de Europa), ii) reconstruir los diferentes glaciares reconocibles en el mencionado conjunto montañoso, y iii) establecer las principales fases de su evolución glaciar.

\section{II. ÁREA DE ESTUDIO}

El área de estudio se circunscribe al Macizo Occidental de los Picos de Europa, también denominado como Macizo del Cornión (Figura 1). Los Picos de Europa constituyen, sin lugar a dudas, el conjunto montañoso de mayor entidad desde el punto de vista de su extensión y altitud de las Montañas Cantábricas (Torrecerredo, 2648 m). Están compuestos por tres macizos (el ya mencionado, el Central o de los Urrieles y el Oriental o de Ándara). Dichos macizos están individualizados por profundos cañones fluviokársti- 
cos tajados por los ríos Dobra, Cares, Duje y Deva, e integrados principalmente por calizas del Carbonífero, organizadas en sucesivas escamas cabalgantes de rumbo aproximado E-O y vergencia hacia el Sur. Es por ello que, desde el punto de vista morfoestructural, los Picos de Europa se organicen en una sucesión de dorsos o espaldares de cierta inclinación en las orientaciones Norte y abruptos frentes hacia el Sur (Figura 2). Este armazón morfoestructural ha sido profusamente transformado por la erosión fluvial, los glaciares cuaternarios (Frochoso y Castañón, 1998; Gale y Hoare, 1997; GonzálezTrueba, 2005, 2007a; Serrano et al., 2012, 2013), los procesos kársticos (Miotke, 1968) y retocado por la morfodinámica periglaciar relicta y actual (Castañón y Frochoso, 1998; Serrano y González-Trueba, 2004).

\section{METODOLOGÍA}

En este trabajo se han reconstruido las fases glaciares del Macizo Occidental de los
Picos de Europa a partir de las evidencias de campo observadas, de la ejecución de cartografía geomorfológica (ejemplificada en la Figura 6) que sigue el método RCP 77 del Centre National de la Recherche Scientifique (CNRS; Joly, 1997) aunque con adaptaciones propias (Ruiz-Fernández, 2011), así como de la realización de dataciones absolutas. En este sentido, se han obtenido manualmente tres secuencias sedimentarias de $8,5,4$ y $1,82 \mathrm{~m}$ de longitud en las vegas del Bricial (la primera) y Belbín respectivamente (las otras dos), que han sido objeto de trabajos previos (Nieuwendam et al., 2016; Ruiz-Fernández et al., 2016a, 2016b) y otros en curso. Cuatro muestras con contenido orgánico han sido datadas por $\mathrm{C} 14$ en los laboratorios GADAM Centre (Polonia), Centre d'Études Nordiques (Canadá) y Centro Nacional de Aceleradores (España) (Tabla 1). La calibración de las edades C14 se realizó con el programa CALIB 7.0 y la curva IntCal13. 


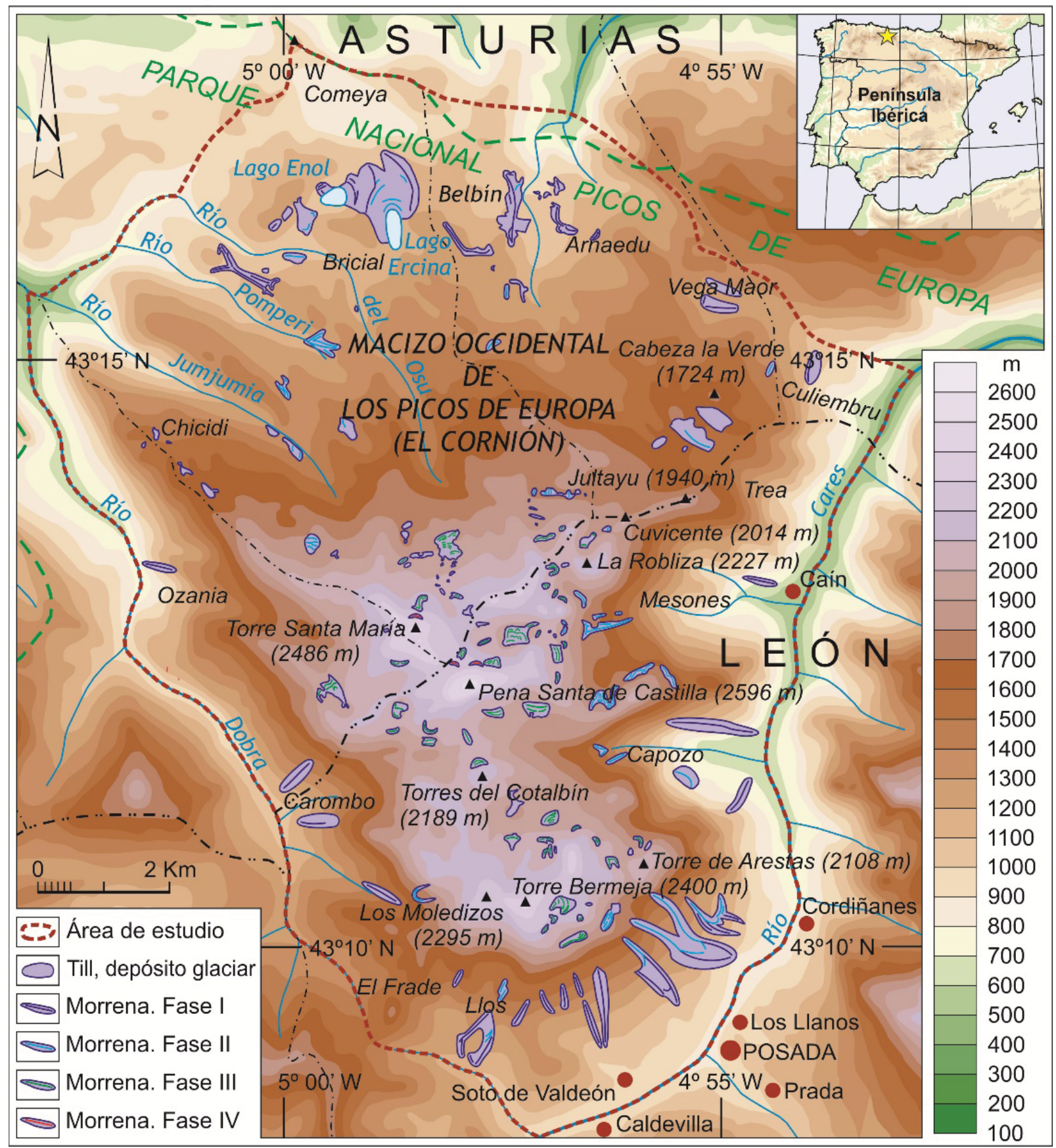

Fig. 1. Localización del área de estudio que incluye la representación de los complejos morrénicos depositados en cada una de las cuatro grandes fases glaciares identificadas en el Macizo del Cornión. 
Tabla 1. Descripción y resultados de las dataciones de C14 efectuadas en las vegas de Belbín y del Bricial.

\begin{tabular}{|c|c|c|c|c|c|c|}
\hline $\begin{array}{l}\text { Código de la } \\
\text { muestra }\end{array}$ & $\begin{array}{c}\text { Contexto } \\
\text { geomorfológico }\end{array}$ & $\begin{array}{l}\text { Material } \\
\text { datado }\end{array}$ & $\begin{array}{l}\text { Profundidad } \\
\text { (m) }\end{array}$ & Método & Edad C14 & $\begin{array}{c}\text { Edad } \\
\text { calibrada } \\
(\text { años cal BP) }\end{array}$ \\
\hline ULA-4662 & $\begin{array}{l}\text { Rellano de } \\
\text { obturación gla- } \\
\text { ciar de Belbín }\end{array}$ & $\begin{array}{c}\text { Bulk } \\
\text { sediment }\end{array}$ & 5,39 & AMS & $32.530 \pm 430$ & $\begin{array}{c}36.718 \pm 1.203 \\
(95 \%)\end{array}$ \\
\hline CNA2346.1.1 & $\begin{array}{l}\text { Rellano de } \\
\text { obturación gla- } \\
\text { ciar de Belbín }\end{array}$ & $\begin{array}{c}\text { Bulk } \\
\text { sediment }\end{array}$ & 3,57 & AMS & $23.120 \pm 240$ & $\begin{array}{c}27.363 \pm 425 \\
(95 \%)\end{array}$ \\
\hline Gd-18436 & $\begin{array}{c}\text { Turbera en } \\
\text { interior de } \\
\text { depresión } \\
\text { glaciokárstica } \\
\text { (vega del Bricial) }\end{array}$ & Turba & 8,00 & $\begin{array}{c}\text { C14 } \\
\text { convencio- } \\
\text { nal } \\
\text { (GPC) }\end{array}$ & $9.690 \pm 260$ & $\begin{array}{c}11.150 \pm 900 \\
(95 \%)\end{array}$ \\
\hline Gd-15989 & $\begin{array}{c}\text { Turbera en } \\
\text { interior de } \\
\text { depresión } \\
\text { glaciokárstica } \\
\text { (vega del Bricial) }\end{array}$ & Turba & 2,80 & $\begin{array}{c}\text { C14 } \\
\text { convencio- } \\
\text { nal } \\
(\mathrm{GPC})\end{array}$ & $3.420 \pm 95$ & $\begin{array}{c}3.675 \pm 235 \\
(95 \%)\end{array}$ \\
\hline
\end{tabular}

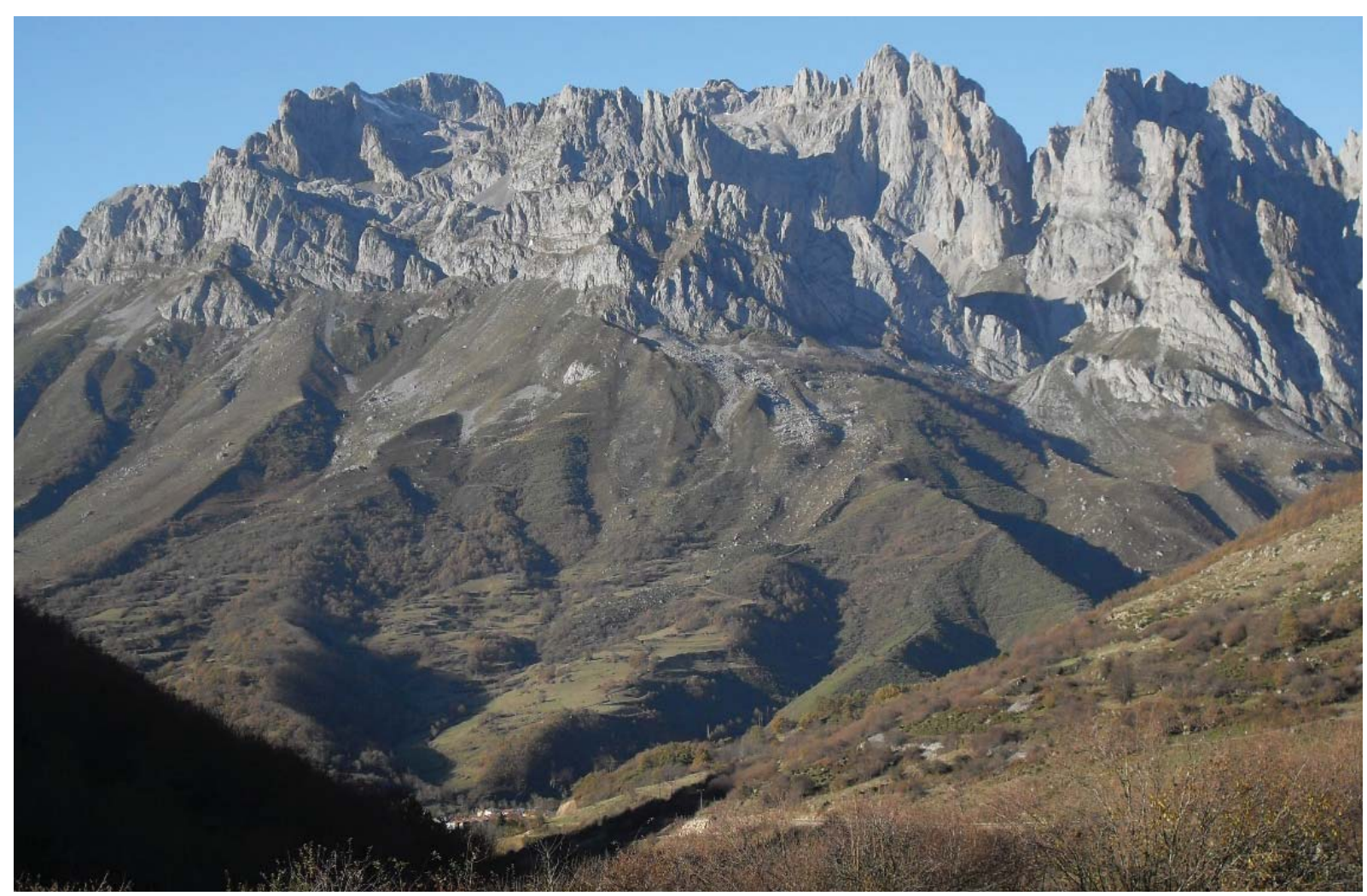

Fig. 2. Escarpe calcáreo meridional del Macizo del Cornión cabalgando sobre los materiales detríticos que arman las laderas que descienden hacia la depresión de Valdeón, pertenecientes ya a otra unidad geológica diferente de la de Picos de Europa (la del Pisuerga-Carrión). A los pies del citado escarpe pueden reconocerse numerosos complejos morrénicos depositados por las lenguas glaciares que ocuparon la vertiente Sur del Cornión durante la Última Glaciación. 


\section{RESULTADOS Y DISCUSIÓN}

\section{Formas de erosión}

Circos glaciares. En el Macizo Occidental de los Picos de Europa se han identificado 59 circos glaciares, con una altitud máxima comprendida entre 1.624 y $2.596 \mathrm{~m}$ (media de $2.223,9 \mathrm{~m}$ ) y una altitud mínima de entre 1.431 y $2.240 \mathrm{~m}$, registrándose en este caso una frecuencia máxima entre 1.990 y $2.100 \mathrm{~m}$ y una media de $1.930,2 \mathrm{~m}$. La orientación N aglutina el $39 \%$ de los circos, la NE el 18,6\%, la S el 11,9\%, la NW el 10,2 $\%$, las orientaciones SW y W suponen en ambos casos el 5,1 \% y la SE el 3,4\%. El 96,6 $\%$ de los circos se han labrado sobre calizas carboníferas, y solamente dos $(3,4 \%)$ se han formado sobre calizas y pizarras. Los circos glaciares presentan una anchura media de 466,53 y una longitud media de 294,92 m, de ahí que su superficie media sea bastante reducida (11,03 ha.; Ruiz-Fernández et al., 2009).

Artesas. En el Cornión las artesas glaciares son en general formas poco marcadas, desarrollándose fundamentalmente en torno a la plataforma de Enol a partir de antiguas depresiones kársticas dispuestas de forma sucesiva y valles secos retrabajados por el hielo (Ruiz-Fernández y Serrano, 2011), así como a favor de las canales que descienden hacia los ríos Cares y Dobra. En la parte Norte del macizo destaca por su gran desarrollo y ejemplar morfología la artesa que arranca en sentido NNW a partir de los Jous de Resecu. Otras artesas destacables son la de la Canal Tras la Envernosa, que presenta un marcado perfil en $U$ y una morfología glaciar erosiva muy nítida, con excelentes ejemplos de rocas aborregadas. Cabe destacar, asimismo, las artesas labradas en las canales de Ozania y Capozo.

Cubetas glaciokársticas (jous). Las dimensiones de estas depresiones son variables, desde grandes hoyas con longitudes próximas al kilómetro como el Jou Luengo o los Hoyos del Caballo, e incluso superiores (Jou Santo), a pequeñas cubetas de apenas 100 a 200 m de diámetro. En planta adquieren formas ovaladas, más o menos circulares e incluso estrelladas, y se distribuyen a lo largo de las principales líneas de fracturación local. La sucesión de grandes jous y umbrales determina el perfil escalonado tan característico de los valles glaciares del Cornión.

Umbrales y rocas aborregadas. Los umbrales son formas muy comunes en el macizo, tanto en el interior y el borde inferior de los circos (Cemba Vieya, Peña Santa Norte, los Basares), como separando unas cubetas glaciokársticas de otras (umbral existente entre el Jou de los Asturianos y el Jou Santo), e incluso compartimentando alguna de estas grandes hoyas en depresiones menores internas (Jou Santo). En el Cornión también son muy abundantes las rocas aborregadas, especialmente en las partes intermedias del macizo, en las que la actividad de los glaciares desarrolló una intensa labor erosiva. Este tipo de formas se puede contemplar, entre otras áreas, en las canales que descienden tanto hacia el Dobra (Carombo, Ozania), como hacia el Cares (Mesones, Trea, Capozo, Tras la Envernosa), así como en el tendido espaldar que, en el Norte del macizo, desciende desde la primera línea de cumbres hasta la plataforma de Enol (Figura 3A y 3B). 

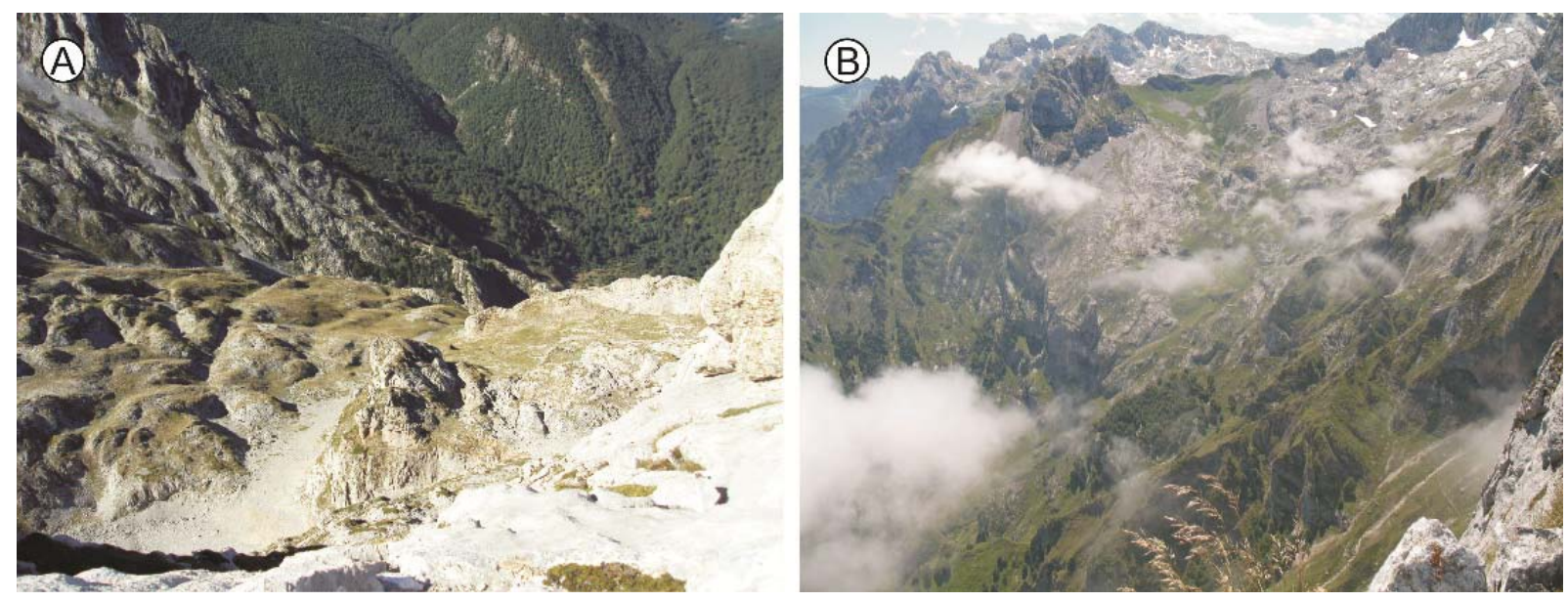

Fig. 3. En las canales de Carombo (A) y Mesones (B) son bien visibles los efectos de la ablación glaciar, que dio lugar a amplias superficies pulidas y molduradas (retocadas posteriormente por la karstificación), en las que se conservan numerosos ejemplos de rocas aborregadas.

Estrías y acanaladuras. En los materiales carbonatados, como es el caso, estas morfologías de pequeña escala son rápidamente borradas por la disolución kárstica postglaciar, de tal manera que en los sectores del Cornión ocupados por los hielos pleistocenos prácticamente no se conservan. Tan sólo es posible contemplar estas microformas en algunos enclaves que han permanecido protegidos por material morrénico $\mathrm{u}$ otras formaciones superficiales, y que han sido puestos al descubierto recientemente debido a la apertura de sendas, como ocurre en Arnaedo (Figura 4A) y las Barrastrosas (Figura 4B y 4C). También se pueden observar estrías y acanaladuras en las paredes de algunas artesas glaciares, especialmente cuando hay extraplomos que han protegido dichas for- mas de la acción del agua y, en consecuencia, de la corrosión kárstica, como se puede observar en la Canal de Ozania, a 1.200 m de altitud, en cuya pared izquierda conforme al sentido del flujo glaciar, intensamente moldurada, es posible contemplar numerosas estrías y acanaladuras que adaptan su inclinación ladera abajo con el aumento de la pendiente (Figura 5A y 5B). En cambio, las estrías se conservan nítidamente en los tres ámbitos que han estado glaciados durante la Pequeña Edad del Hielo (PEH); la Forcadona, Peña Santa Norte (Figura 4D y 4E) y la Cemba Vieya (Figura 4F). En ellos, la karstificación no ha tenido tiempo de progresar desde su deglaciación, de ahí que la morfología generada por la ablación glaciar sea aún muy fresca. 

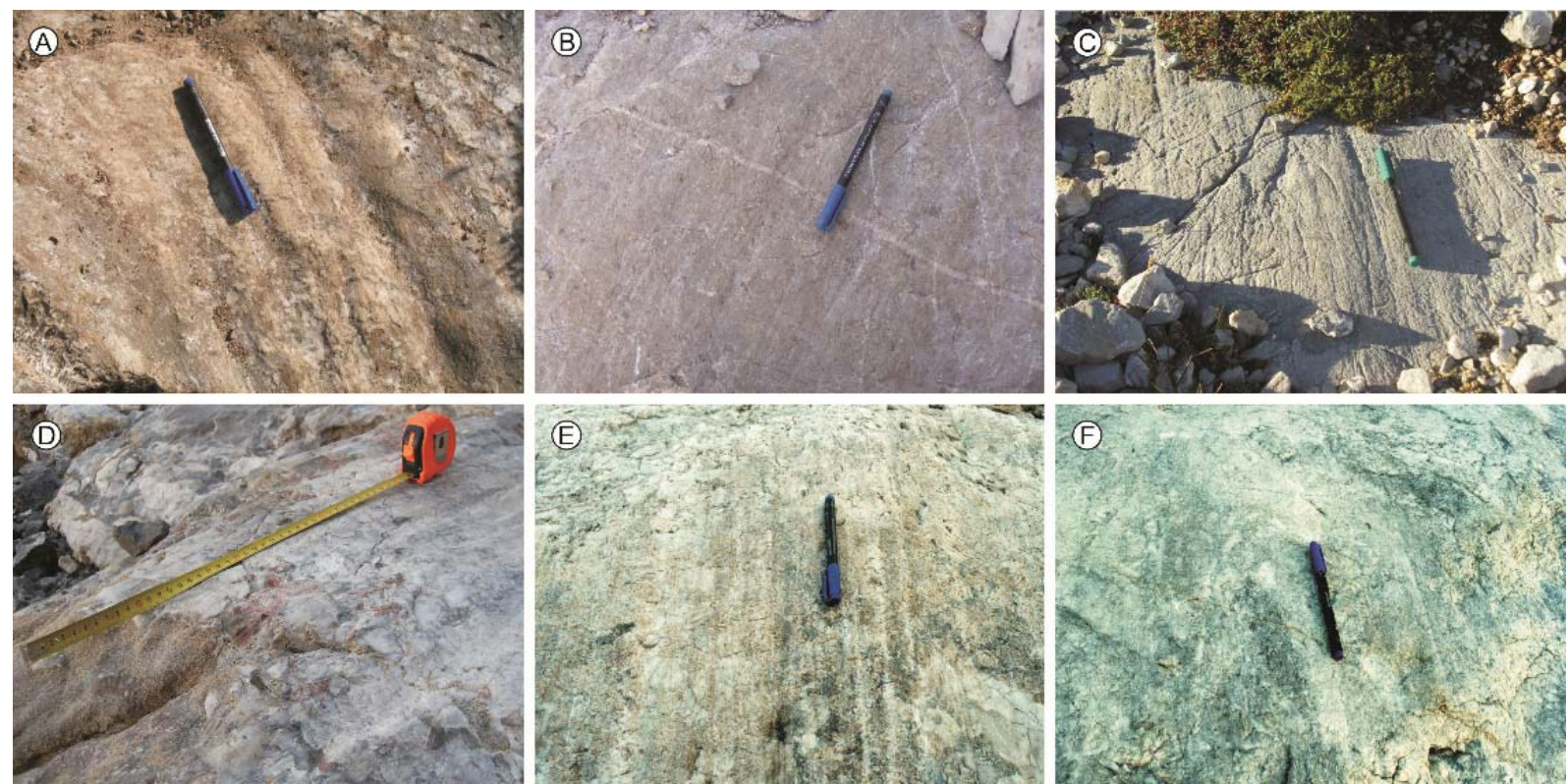

Fig. 4. Detalle de estrías glaciares sobre afloramientos calcáreos puestos al descubierto por la apertura de sendas en Arnaedu (A) y las Barrastrosas (B y C). Sustrato pulido y estriado perfectamente conservado, generado por los glaciares de la PEH de Peña Santa Norte (D y E) y la Cemba Vieya (F).
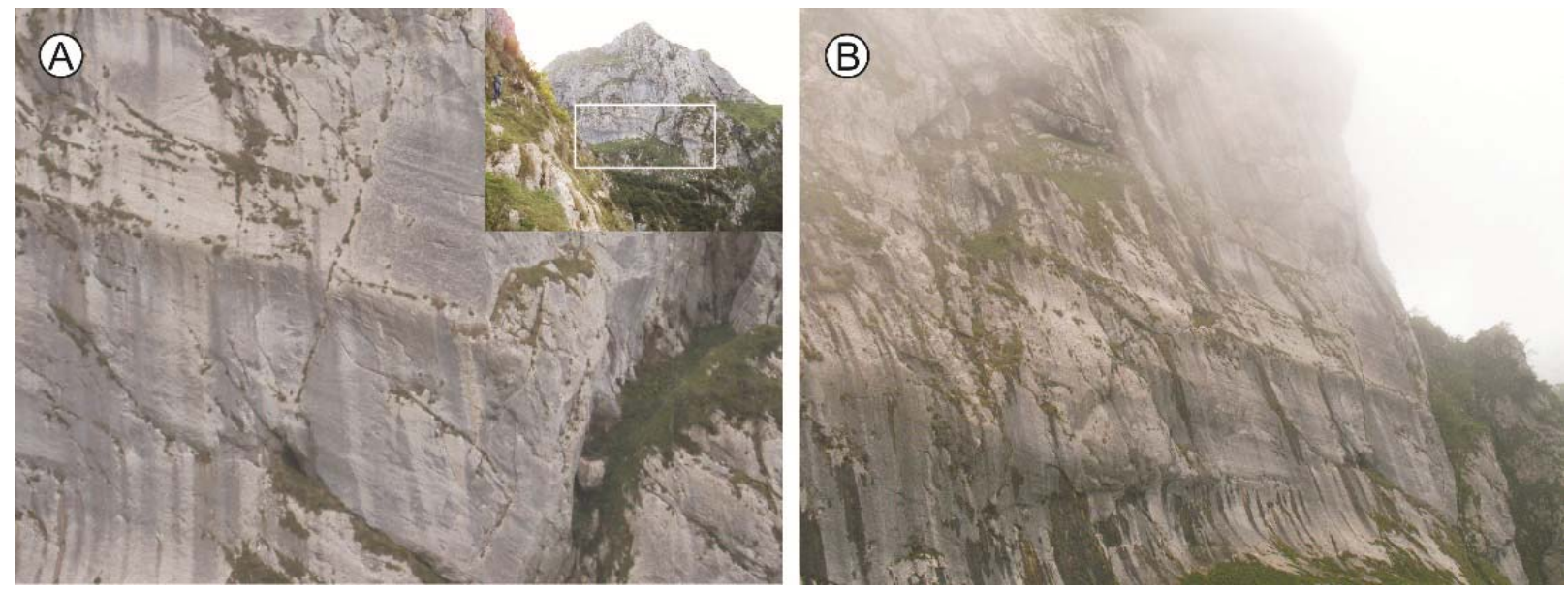

Fig. 5. (A) Estrías y acanaladuras glaciares en la pared SE de la canal de Ozania, y (B) detalle de las mismas morfologías.

\section{FORMAS DE ACUMULACIÓN}

Pese a ser buenos indicadores, las huellas de ablación glaciar no deben usarse de forma exclusiva para estudiar el glaciarismo desarrollado en un determinado ámbito, sino que han de ser complementadas con el estudio de los depósitos sedimenta- rios generados por las masas de hielo. En el Cornión es posible reconocer diferentes morfologías y tipos de acumulaciones detríticas generadas directa o indirectamente por los glaciares. A continuación, se describirá brevemente cada una de ellas, pues en el apartado referido a la reconstrucción glaciar se profundizará en esta cuestión. 
Cordones morrénicos. Son muy abundantes en las partes medias y bajas del Cornión, destacando, entre otras, las existentes en Pandecarmen, Ercina, Belbín, Parres, las Vegas, el Vallejón de las Horcadas, Arestas, Hoyobladas y Llos. Por su parte, las morrenas frontales adquieren una disposición perpendicular a la dirección del hielo y son también muy comunes, especialmente en la alta montaña, asociadas en este caso a las fases glaciares desarrolladas en altitud, alguna de ellas muy pulsadora como se tratará posteriormente.

Morrenas de fondo. Se sitúan habitualmente en el fondo de los valles glaciares, como es el caso de la generada en torno a Brañarredonda, entre las morrenas laterales de Belbín y Espines.

Bloques erráticos. Abundan en numerosos sectores del macizo, como Ordiales, Mesones, las Barrastrosas, la cabecera del río Jumjumia, la vertiente Sur de Peña Santa de Castilla, las inmediaciones del Jou Sin Tierri, etc.

Rellanos de obturación. En algunos casos las morrenas han provocado la obturación de diversos enclaves y la formación de pequeños depósitos de tipo glaciolacustre, como los de Belbín, Parres, las Mantegas, las cercanías de Arnaedo y Brañarredonda (Figura 6). Dos sondeos efectuados en la majada de Belbín ponen de manifiesto que el relleno sedimentario de la depresión sobre la que se asienta la vega se compone esencialmente de materiales arcillosos de tonos grisáceos y origen lacustre, que se depositaron sobre otros de tipo periglaciar integrados por gravas calcáreas y pizarrosas aristadas e intercaladas en una matriz arcillosa de tonos pardos (Ruiz-Fernández et al., 2016a, 2016b). La morfología de estos rellanos y su funcionamiento difiere del de las terrazas de obturación glaciar bien desarrolladas, ya que en este caso parte de las escorrentías recibidas se infiltraban en el macizo calizo, al igual que sucede actualmente.

\section{RECONSTRUCCIÓN DE LOS GLACI- ARES DEL MACIZO OCCIDENTAL DE LOS PICOS DE EUROPA: EXTENSIÓN, DINÁMICA Y FASES DIFERENCIADAS}

Las huellas glaciares erosivas y sedimentarias descritas en los apartados precedentes permiten diferenciar en el Macizo del Cornión cuatro grandes fases glaciares: Fase de Máxima Extensión del Hielo (I), Fase Interna (II), Fase Glaciar de Altitud o III (Tardiglaciar) y, por último, Fase de Glaciares de Fondo de circo o IV (PEH). En las páginas siguientes se efectuará una descripción detallada de la extensión y características de los aparatos glaciares existentes en cada una de las fases, así como una aproximación a su dinámica y un ensayo cronológico.

\subsection{Las huellas de la Última Glaciación}

\subsubsection{Reconstrucción glaciar}

\subsubsection{El glaciar de Enol}

El glaciar de Enol, modelado en la vertiente Norte del Cornión a favor del largo espaldar rocoso que conecta la primera alineación de cumbres del macizo con la plataforma homónima, es el que mayor desarrollo adquirió de todos los existentes, con $8,5 \mathrm{~km}$ de ancho por 7 de largo. Emitió hasta once lenguas a modo de digitaciones (Chicidi, nacimiento del Jumjumia, Pomperi, el Osu, Enol, Ercina, Belbín - Espines, Vega Maor, Ostón, Sollambriu y Trea) (Figuras 1 y 11). 
La primera de ellas llegó a descender hasta el sector de la Campera de Chicidi (terminación occidental del macizo). Estaba alimentada por una difluencia procedente del circo excavado en la cara Norte de los picos Cotalba (2026 m) y Torre de la Canal Vaquera $(2.089 \mathrm{~m})$, que pasó hacia el área de Ordiales a través de un collado situado al Norte de la primera de las cimas citadas. Como prueba de la mencionada difluencia, en la Vega de Ordiales se puede reconocer un manto morrénico, además de numerosos bloques erráticos, algunos situados en la culminación de un afloramiento calizo en resalte. Los restos sedimentarios de origen glaciar más bajos depositados por esta lengua glaciar se encuentran en torno al Jou de los Redondos y la Campera de Chicidi. En el citado jou hay material morrénico, al igual que al Norte del mismo, donde además se conserva una acumulación de bloques que interpretamos como erráticos, pues algunos de ellos se localizan sobre umbrales, lo que descarta que pudieran deberse a otros procesos. Finalmente, en la Campera de Chicidi, a $1.480 \mathrm{~m}$ de altitud, se sitúan los bloques erráticos más bajos. Aguas abajo de este enclave el valle experimenta un importante cambio morfológico. Se vuelve mucho más angosto y encajado y ya no presenta huellas de ablación glaciar ni más restos morrénicos. La parte final del mismo se convierte en una angosta canal de aludes que desciende bruscamente hacia el río Jumjumia. Por tanto, situamos el frente de la lengua que descendió entre Ordiales y la Campera de Chicidi a la cota antes señalada. 


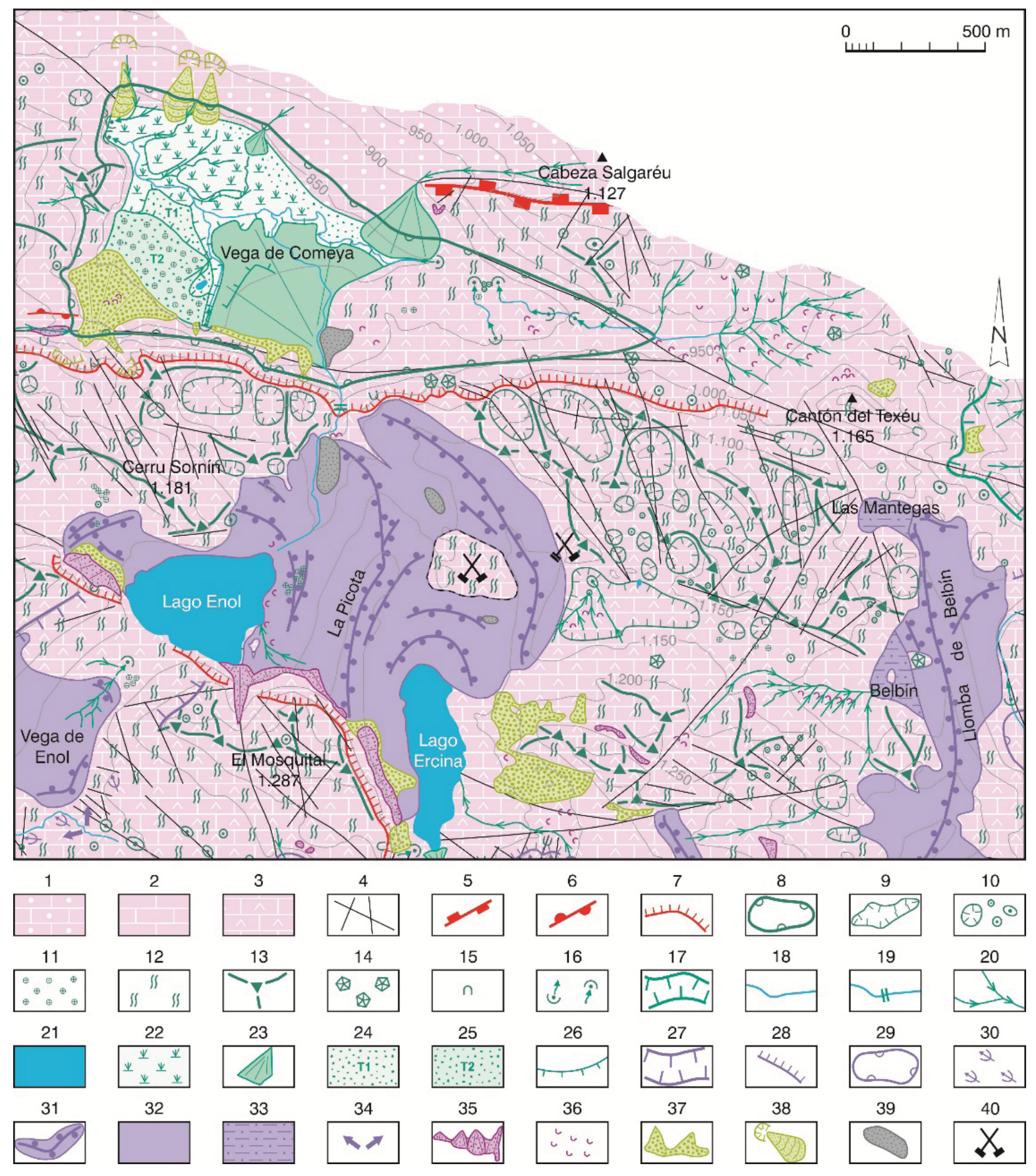

Fig. 6. . Cartografía geomorfológica del entorno de los Lagos de Covadonga. 1.- Cuarcitas de la Formación Barrios (Ordovícico). 2.- Calizas de Montaña (Carbonífero). 3.- Calizas de Picos de Europa (Carbonífero). 4.- Fallas y fracturas. 5.- Capa subvertical en resalte. 6.- Capa subvertical erosionada. 7.- Escarpe rocoso. 8.Poljé. 9.- Uvala. 10.- Dolinas. 11.- Boches. 12.- Campo de lapiaces. 13.- Relieve calcáreo residual. 14.- Porrones calcáreos. 15.- Cueva, abrigo rocoso. 16.- surgencia y sumidero. 17.- Garganta, cauce encajado. 18.- Río. 19.Cascada. 20.- Surcos de arroyada. 21.- Lago. 22.- Turbera, área encharcada. 23.- Cono torrencial. 24.- Terraza fluvial T1. 25.- Terraza fluvial T2. 26.- Escarpe de terraza fluvial. 27.- Artesa glaciar. 28.- Umbral glaciar. 29.- Cubeta glaciokárstica. 30.- Rocas aborregadas. 31.- Morrena. 32.- Till, depósito glaciar. 33.- Rellano de obturación lateral. 34.- Difluencia glaciar. 35.- Taludes y conos de derrubios. 36.- Lóbulos de solifluxión. 37.Desprendimiento. 38.- Deslizamiento. 39.- Escombrera. 40.- Mina inactiva. 
La lengua que descendió desde Ordiales hacia el NW estaba mal alimentada. De hecho, en el área de Ordiales no se llegó a formar un verdadero circo bien excavado. Este valle glaciar estuvo alimentado en gran medida por la difluencia proveniente del collado ubicado al $\mathrm{N}$ del pico Cotalba. Sin embargo, el till que recubre parte de la Vega de Ordiales y que se puede observar también en las cercanías de Ordiales de Abaju y en el Jou los Redondos, junto con los bloques erráticos situados en posiciones topográficamente destacadas (en ocasiones claramente alóctonos con respecto a la litología calcárea local), no dejan lugar a dudas sobre el pasado glaciar de este sector del macizo.

La siguiente lengua hacia el Este fue la que alcanzó la cabecera del río Jumjumia. Entre Ordiales, Chicidi y el nacimiento del Jumjumia, el glaciar depositó material morrénico en el fondo de varios jous a cotas de $\sim 1.360 \mathrm{~m}$ de altitud, así como numerosos bloques erráticos. Estos materiales enlazan con un manto morrénico situado a 1.280 $\mathrm{m}$ de altitud en la margen izquierda del río Jumjumia. El mencionado manto es poco espeso y cuenta con gran cantidad de cantos y bloques en superficie. Finalmente, en la misma margen, pero aguas arriba (área de los Güeyos del Jumjumia), existe más material morrénico de gran potencia y con morfologías arqueadas.

El extenso y complejo conjunto morrénico de Pandecarmen delimita el borde izquierdo del valle glaciar del río del Osu y el derecho del valle del Pomperi (Figura 1). Los materiales situados a mayor altitud y más internos se encuentran en el Jou del Porru, donde hay un arco morrénico muy marcado, depositado por la lengua que descendió por el valle del Osu. No obstante, parte del hielo pasó al menos unos centenares de metros hacia el SE de la cubeta (y por tanto hacia el valle glaciar contiguo del Pomperi), a través de una escotadura, como evidencian los bloques erráticos de caliza dispersos sobre las dolomías que afloran in situ. Al Este de los citados bloques y al Norte del Jou Chico se puede observar otra loma morrénica que pone de manifiesto igualmente el paso de una pequeña parte del hielo al otro lado de la cresta que hace de divisoria entre ambos valles glaciares (Osu y Pomperi). Por otro lado, entre el Porru Llaguiellu y la pista que discurre hacia el aparcamiento de Pandecarmen hay dos cordones morrénicos que van perdiendo altitud progresivamente. El más interno queda interrumpido antes de alcanzar la pista y está menos marcado, mientras que el externo es más voluminoso y continúa valle abajo con algunas interrupciones hasta alcanzar los $1.027 \mathrm{~m}$, siendo ésta la altitud más baja a la que se han encontrado sedimentos de origen glaciar para el valle del Osu. En la zona distal hay otra morrena más externa y de planta arqueada que enlaza con la anterior. El conjunto sedimentario que nos ocupa se completa con un cordón adosado a la ladera que se desarrolla entre Pandecarmen y las inmediaciones del Mirador del Rey, señalando la máxima extensión de la lengua glaciar que descendió por el valle del Pomperi.

La masa de hielo procedente del área del Bricial se dividió en dos lenguas al llegar a la Vega de Enol. Una discurrió hacia el NW (la del río del Osu, descrita en el párrafo anterior), mientras que la otra se dirigió hacia el NE, labrando la cubeta ocupada actualmente por el Lago Enol y depositando el complejo morrénico que envuelve al citado lago. El borde septentrional de ambas lenguas (río del Osu y Enol), así como el espesor alcanzado por el hielo, se puede reconstruir a partir de 
los restos de till visibles en la ladera Sur de la alineación definida por el Porru les Llampes (1.1.75 m), el Cuetu Espineres (1.235 m) y la Porra de Enol (1.269 m). En función de tales testimonios el glaciar tenía unos $120 \mathrm{~m}$ de potencia a la altura de la Vega de Enol.

Mientras que la lengua proveniente del Bricial se dividió en dos, para fluir una hacia la Pandecarmen y la otra hacia Enol y Sornín, perdiendo en consecuencia espesor y capacidad modeladora, la que llegó a Ercina edificó un complejo morrénico mucho más voluminoso y destacado que el de Enol, existiendo una diferencia de cota de 70 metros entre la morrena lateral de la Picota, generada por la digitación de Ercina, y la de Sornín, depositada por la difluencia de Enol (Figuras 1 y 6). Por tanto, la morrena de la Picota no puede ser considera de ningún modo una morrena intermedia desde el punto de vista genético. Se trata simplemente de la morrena lateral izquierda de la lengua de Ercina, cuyo frente se situó a 1.050 m s.n.m. Al Oeste de esta morrena hay adosado otro complejo morrénico, el de Sornín, que constituye la morrena lateral derecha de la lengua de Enol y que, como se ha mencionado, alcanza mucha menor cota.

La siguiente digitación del glaciar de Enol es la de Belbín - Espines. Los cortes abiertos por una senda en la morrena lateral de Belbín permiten comprobar un desgaste importante en los bloques, cantos y gravas calcáreas que afloran, fruto ya de un largo transporte desde la cabecera del glaciar a la zona distal. Una pequeña porción de la lengua de hielo penetró hacia la depresión kárstica que configura la Vega las Mantegas, situada inmediatamente al Norte de Belbín, tal y como evidencia el cierre morrénico algo desmantelado que ocupa la porción más oriental de la vega. En consecuencia, el sector centro-occidental de la citada depresión quedó obturado por el glaciar, al igual que la propia Vega de Belbín (Figura 6). Entre la morrena lateral izquierda de Belbín (Figura 7) y la Vega de Espines, donde se encuentra el retazo más bajo de la morrena lateral derecha, el glaciar saltó un gran umbral para fundirse sin dejar depósitos asociados (si existieron fueron desmantelados por la erosión fluvial posterior), por lo que el frente de esta lengua lo situamos aproximadamente a $950 \mathrm{~m}$ s.n.m. Hay huellas claras de erosión glaciar en la zona del umbral terminal, por lo que evidentemente el hielo lo modeló antes de precipitarse por el gran escarpe. A partir de este salto hay un cambio morfológico notable en el valle, que se convierte en una garganta muy encajada modelada por el río Casaño.

En la terminación oriental de la Vega de Arnaedo se aprecia till disperso, así como una pequeña loma morrénica adosada contra la vertiente. Se distinguen bloques, cantos y gravas bastante rodados, por lo que no han podido venir desde la ladera de la propia vega. Todo apunta a que el glaciar entraba en Arnaedo desde el Sur, dejando los citados materiales empotrados contra la ladera E, y depositando un arco morrénico perfectamente conservado hacia el Noroeste de la vega, en cuyas inmediaciones se pueden apreciar estrías sobre un afloramiento rocoso puesto al descubierto recientemente por una senda (Figura 4A). Aguas abajo de la Vega de Arnaedo hay una morrena lateral de forma arqueada que enlaza con la que desciende y luego se incurva hacia la Majada de Parres (Figura 1). Entre el complejo morrénico de la Vega de Arnaedo y la morrena lateral arqueada citada anteriormente, se formó un pequeño rellano de obturación.

En la terminación NE del glaciar de Enol cabe citar la difluencia de la masa de hielo al 


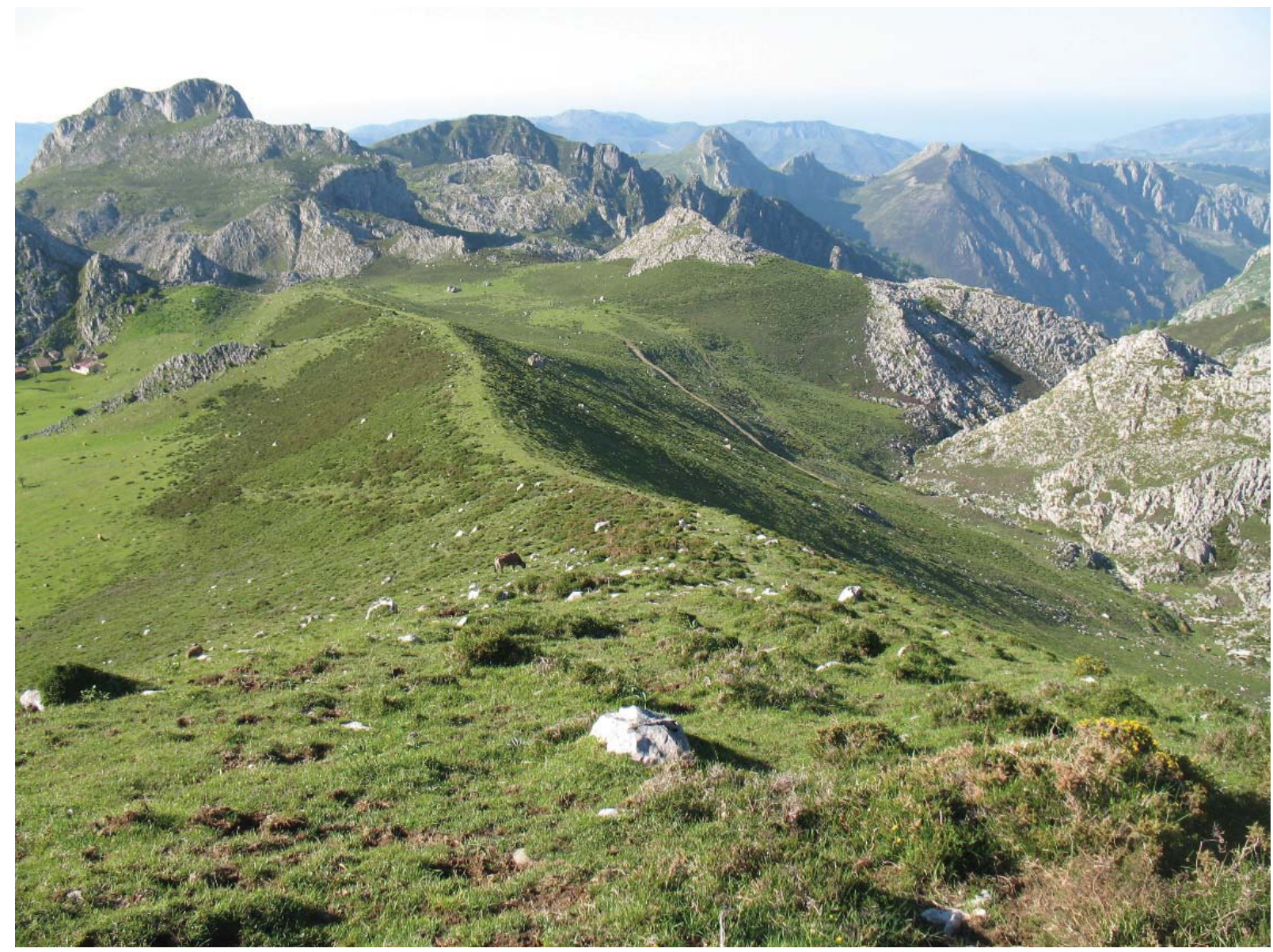

Fig. 7. Morrena lateral izquierda de la Llomba de Belbín.

alcanzar la Cabeza Cayarga (1528 m). El flujo glaciar, procedente de las inmediaciones de Ario (Cabeza Julagua, etc.) quedó dividido en dos partes. Una pequeña lengua descendió hacia el NE entre la citada Cabeza Cayarga y la Cabeza Muxa hasta alcanzar Vega Maor, donde se depositó un complejo morrénico frontal a unos $1.230 \mathrm{~m}$ integrado por dos pequeñas morrenas, así como por abundante till disperso (Figura 1); mientras que el resto del hielo se dirigió hacia el NW, generando los complejos morrénicos antes mencionados de Arnaedo, Parres y Espines, que dibujan el límite oriental del valle glaciar de Belbín - Espines. Por lo tanto, el Colláu Xerra Buena, situado inmediatamente al Norte de la Cabeza Cayarga, no estuvo glaciado durante la Última Glaciación, al igual que el espacio comprendido entre el Este de Vega Maor, la Vega los Corros y el Valle la Texa, en las cercanías de Ostón.

Hacia el Este de Cabeza Muxa descendió otra pequeña lengua cuyo frente se situó a 1.000 m s.n.m, alcanzando el arranque de la Canal de Culiembru (Figura 1). Como testimonio sedimentario de la extensión alcanzada por la citada lengua, en Ostón se conserva una morrena de forma arqueda y perfil achatado y disimétrico. Las dos últimas digitaciones del glaciar de Enol discurrieron por sendas canales, las de Sollambriu y Trea, que descienden con gran pendiente hacia la garganta del Cares. En este caso no se conservan testimonios sedimentarios, por 
lo que los únicos datos en los que podemos apoyar la reconstrucción de dichas lenguas son las huellas glaciares erosivas, así como el cambio morfológico experimentado por las canales. En función de estos criterios, situamos los frentes en ambos casos a $\sim 700 \mathrm{~m}$ de altitud.

En el glaciar de Enol existieron numerosas difluencias y también transfluencias de unas lenguas a otras. Del área de la Torre Santa María (2.486 m) el hielo se canalizó en gran medida por la artesa glaciar de Resecu hacia el sector de los Lagos de Covadonga. No obstante, por la Vega el Bolu parte del hielo se incorporó a la lengua procedente de los circos excavados en la vertiente Norte de la alineación de cimas integrada por el Cotalba, el Requexón y las Cumbres de Cebollera; que descendió hacia Vegarredonda y el nacimiento del río Jumjumia. Otra parte del hielo pasó por el Collado los Afrontadorios hacia la Vega de Justillagar y allí volvió a dividirse, para fluir una parte hacia la Redondiella a través del Jou la Fuente y otra hacia la Vega Orrial y la cabecera del río Pomperi. Asimismo, por el Sur el glaciar de Enol también entró en contacto con el de Ozania a través del Collau les Merines y de una escotadura abierta justo al $\mathrm{W}$ de la Torre de Canal Vaquera; así como con el de Mesones, puesto que una parte el hielo acumulado en el Jou Santo fluyó hacia el aparato septentrional tras superar un umbral situado inmediatamente al Norte del Jou de los Asturianos que cuenta con muestras inequívocas de ablación glaciar, además de till y bloques erráticos en su culminación; mientras que otra se dirigió hacia el glaciar de Mesones a través del Boquete. Igualmente, desde la cara E de la Torre del Alba, donde hay un pequeño circo a cuyos pies está el Hoyo de Arenizas, el hielo pasó hacia el glaciar de
Enol por el Jou la Capilla, y también hacia el glaciar de Mesones por la Horcada Miguel y por una brecha que desciende desde el Hoyo Arenizas a las inmediaciones del Boquete, en el sector más occidental del Jou Santo.

Al interior de los complejos morrénicos principales del glaciar de Enol existen otros generalmente de menor entidad, pertenecientes a fases de empuje glaciar posteriores al máximo avance (Fase Interna o II). Así, en el extremo Oeste de la depresión glaciokárstica de las Bobias se conserva un cordón morrénico que presenta la estructura sedimentaria típica del till. En el borde Norte y Este de la vega se extiende también abundante material morrénico. Más al Sur, a los pies de un boquete abierto en el borde meridional de la Vega del Ceñal, se encuentra un arco morrénico a $1.400 \mathrm{~m}$ de altitud. En la Vega Orrial se ha depositado un complejo morrénico integrado por tres cordones en el flanco Sur y dos en la parte Norte. Estas morrenas se formaron como consecuencia de una difluencia de la masa glaciar canalizada por la artesa de Resecu, que pasó hacia la cabecera del río Pomperi a través de un collado con huellas de ablación glaciar netas. En una primera fase el hielo sobrepasó el collado para unirse con los aportes procedentes de la Redondiella y Justillagar, generados por sendas difluencias, constituyendo en conjunto una lengua que descendió por el valle del Pomperi hasta las inmediaciones del Mirador del Rey. Con el inicio de la deglaciación, el hielo derivado de la artesa de Resecu a través del citado collado quedó desconectado de la lengua proveniente de la Redondiella y Justillagar, sedimentándose las citadas morrenas en una fase posterior a la MEH de la Última Glaciación.

En la Redondiella se sitúa otro complejo morrénico abierto en su parte frontal e inte- 
grado por dos morrenas laterales izquierdas y otra derecha de menor dimensión, todas ellas de escasa potencia. En cambio, en la Vega de Justillagar hay abundante till que recubre su porción SE, llegando a vislumbrarse una loma morrénica de disposición arqueada. Finalmente, cabe citar el material morrénico que recubre la Vega de Ario, así como el complejo morrénico de la Vega de Aliseda, en el que se han identificado hasta 6 arcos frontales bien definidos.

\subsubsection{El glaciar de Mesones}

Inmediatamente al Sur del anterior se desarrollaron otros dos aparatos glaciares, los de Ozania y Mesones. Este último contó con un área de acumulación en la que, además de albergar algunas de las cimas de mayor altitud del Cornión, existen profundas depresiones glaciokársticas como el Jou Santo o el Hoyo Piedralengua, muy favorables para la acumulación de grandes espesores de nieve y su transformación en hielo. El citado aparato generó una lengua principal que descendió por la Canal de Mesones hacia Caín, así como otra secundaria colgada en la Canal de Oliseda. Se conservan sedimentos glaciares en diversos puntos de la parte alta de la Canal de Mesones y sus inmediaciones. En la propia canal hay varios arcos morrénicos, así como dos morrenas laterales que descienden hasta $1.570 \mathrm{~m}$ en el caso de la que alcanza una cota más baja. Por su parte, en los Puertos de Cuba se generó un complejo morrénico que desciende hasta $1.750 \mathrm{~m}$ de altitud en el punto más bajo de su porción occidental y hasta $1.730 \mathrm{~m}$ en la parte Este (Figura 8). Hay otro complejo morrénico alojado en la cara $\mathrm{N}$ del Pico de los Cabritos que tiene su frente a $1.500 \mathrm{~m}$ de altitud. Se formó, al igual que los mencionados anteriormente, con poste- rioridad a la MEH de la Última Glaciación, una vez que el glaciar de Mesones retrocede y queda individualizado en masas menores. También abundan los bloques erráticos por toda la canal hasta la altitud de la Majada de Mesones (1.430 m), en muchos casos abandonados por el hielo en posiciones culminantes. La acción de la ablación glaciar es nítida a lo largo de toda la parte media y alta de la canal, siendo posible observar numerosas rocas aborregadas y llambriales con el característico pulido, trastocado en detalle por la karstificación posterior. A partir de 1.200 $\mathrm{m}$ de altitud la canal presenta un gran salto estructural hasta los $750 \mathrm{~m}$ (Figura 9). Los depósitos glaciares más bajos se encuentran al Norte de Caín de Arriba, donde es posible reconocer una morrena citada previamente por González-Trueba y Serrano (2011), que sitúan el frente del glaciar de Mesones a 600 m s.n.m. (Figura 1).

\subsubsection{El glaciar de Ozania}

Se trata de un glaciar de estilo alpino surgido al amparo del amplio recuenco de orientación NW definido por las cumbres de la Torre de Canal Vaquera (2.089 m), el Requexón (2.274 m), las Torres de Cebolleda (2.445 m), la Torre del Medio $(2.467 \mathrm{~m})$, la Torrezuela $(2.322 \mathrm{~m})$, las Torres de las Tres Marías $(2.420 \mathrm{~m})$, las Torres del Torco $(2.416 \mathrm{~m})$, los Estribos (2.300 m), el Diente (2.301 m), la Torre de la Cabra Blanca $(2.320 \mathrm{~m})$, la Garita Cimera $(2.276 \mathrm{~m})$ y la Garita Bajera (1.998 $\mathrm{m})$. Este aparato descendió hasta los $750 \mathrm{~m}$ de altitud, alcanzando el nivel marcado por el río Dobra, tal y como pone en evidencia la morrena lateral adosada a la margen derecha de la canal (Figura 1). En los cortes existentes en el borde de una pista se aprecia claramente la estructura típica del till. 


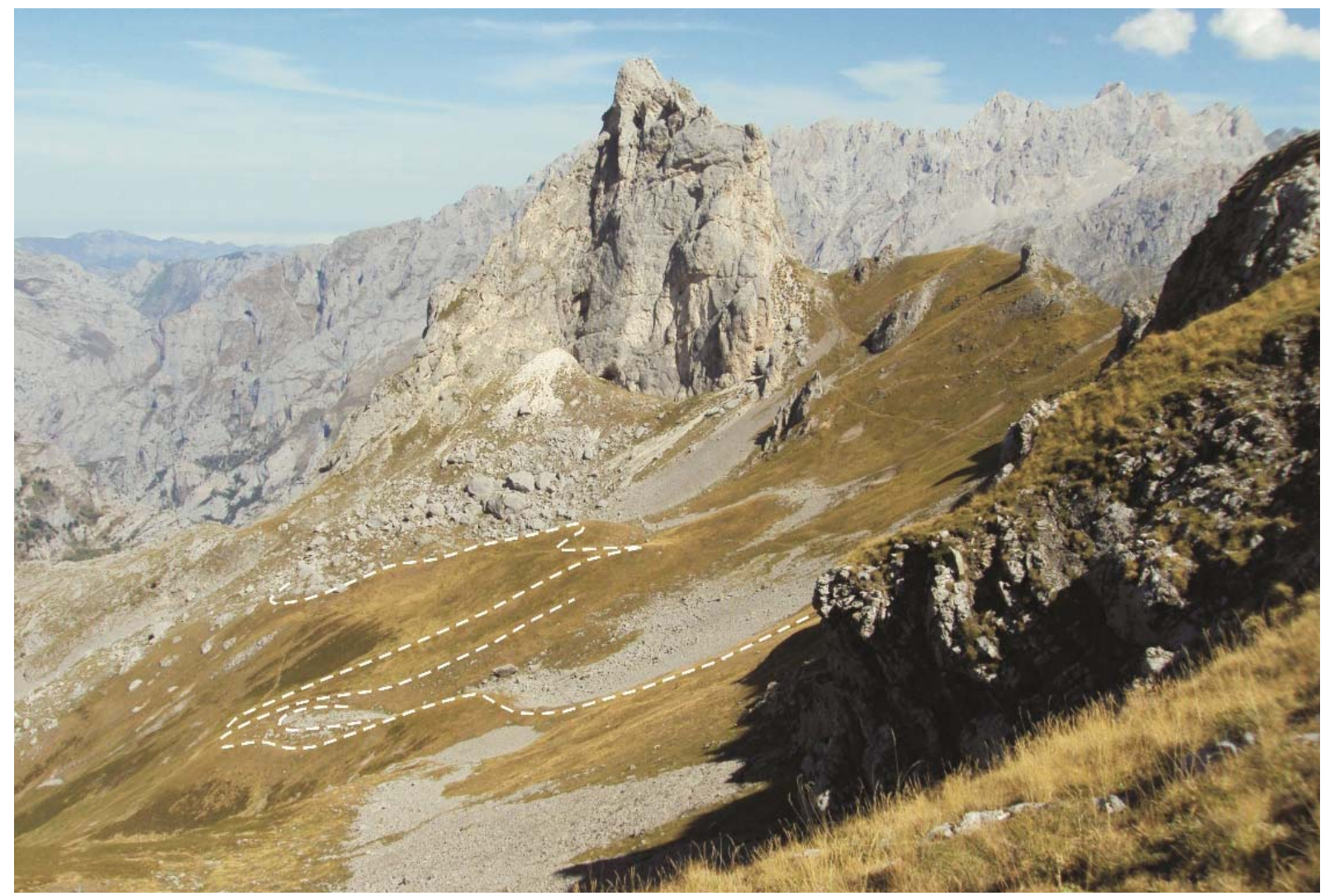

Fig. 8. Complejo morrénico de los Puertos de Cuba.

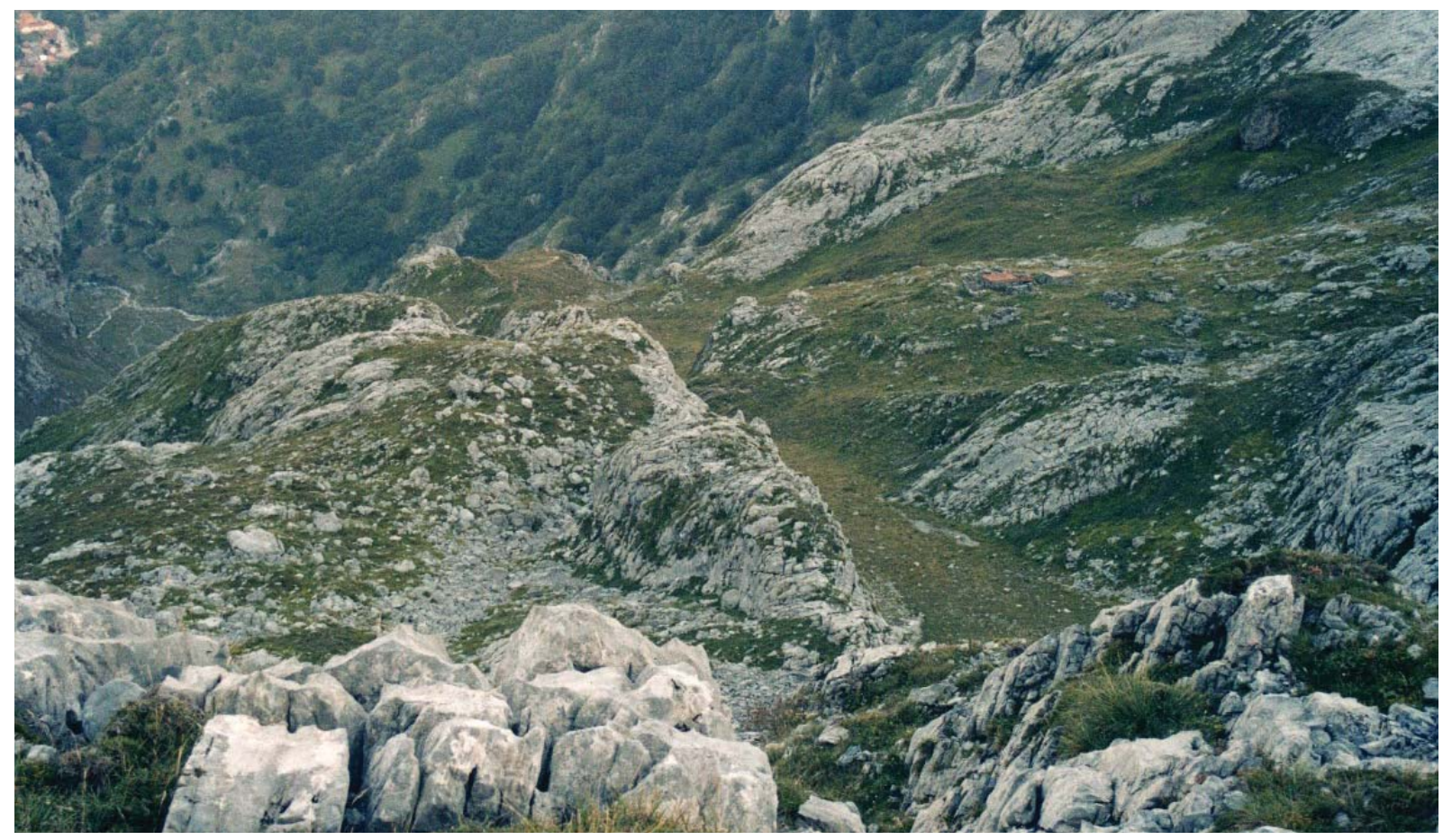

Fig. 9. Material morrénico disperso y bloques erráticos junto a rocas aborregadas en la canal de Mesones a la altura de la majada homónima. Al fondo aparece el pueblo de Caín. 


\subsubsection{El glaciar de Capozo-Carombo}

Constituyó un pequeño campo de hielo delimitado por las alineaciones de cumbres presididas por Peña Santa de Castilla al Norte y la Torre Bermeja al Sur, y con drenaje por el Este hacia la garganta del Cares (canales de Capozo y Tras la Envernosa), por el Oeste hacia la del Dobra (Canal de Carombo), y por el Sur también hacia el Dobra a través de la Canal del Perro y la riega de la Vareda. En la canal de Carombo la morfología glaciar erosiva es nítida hasta $1.250 \mathrm{~m}$, pudiendo ser observadas numerosas rocas aborregadas. A partir de esta altitud a ambos lados de la boca de la canal se conservan dos morrenas laterales que dibujan la extensión máxima del glaciar, cuyo frente abierto se situó a $1.050 \mathrm{~m}$ de altitud, alcanzando la altitud marcada por el Dobra, pero sin llegar a encauzarse valle abajo. En la ladera izquierda de este río aguas abajo de la Vega de Carombo solamente se han encontrado cantos y pequeños bloques de arenisca y pizarra, es decir, clastos provenientes de la meteorización de la litología autóctona, pero en ningún caso restos de till ni bloques calcáreos que pudiesen ser erráticos.

En la Canal de Capozo se conserva una morrena lateral izquierda entre 1.550 y $1.470 \mathrm{~m}$ de altitud, junto a otra lateral derecha más pequeña, dibujando entre ambas un frente que alcanzó la cota más baja de las dos señaladas, perteneciente a una fase de avance menor de la masa de hielo ya dentro de su retroceso generalizado hacia la cabecera. Precisamente a $1.470 \mathrm{~m}$ arranca un cordón morrénico que al principio está adosado a la margen derecha de la canal y luego se separa de la misma, hasta alcanzar los 1.360 $\mathrm{m}$. Se trata de una morrena que señala una lengua glaciar de mayor anchura, potencia y longitud que en el caso anterior. Es posible observar igualmente con gran nitidez las morfologías derivadas de la abrasión glaciar, constituyendo la propia canal una artesa bien definida en la que se conservan buenos ejemplos de rocas aborregadas. Las formas glaciares erosivas son muy claras hasta 1.150 $\mathrm{m}$. A partir de esta altitud hay un gran escarpe estructural que el glaciar saltó para depositar las voluminosas morrenas laterales de las Vegas (especialmente la izquierda) (Figura 1). Éstas evidencian que el glaciar llegó a descender hasta el fondo de la Garganta del Cares a $550 \mathrm{~m}$ de altitud, lo que supone una cota excepcionalmente baja para un frente glaciar a nivel de la Península Ibérica. Parte del hielo que fluyó hacia el Cares lo hizo a través de la Canal Tras la Envernosa, generando en ella una nítida artesa de marcado perfil transversal en U que cuenta también con numerosas rocas aborregadas. A los pies de la citada canal se conserva un depósito morrénico muy voluminoso y de disposición arqueada, aunque abierto por su extremo Norte y caracterizado por el predominio en superficie de grandes bloques; señalando una estabilización del glaciar a $850 \mathrm{~m}$, una vez que las dos masas de hielo (Capozo y Tras la Envernosa), quedaron escindidas.

Por el Collado del Burro, abierto entre las cimas de los Moledizos (2.254 m) y los Picos del Verde $(2.180 \mathrm{~m})$, en el sector SW del macizo, se produjo una difluencia del glaciar de Carombo-Capozo que se encauzó por la Canal del Perro hacia el área del Frade y la riega de la Vareda (afluente del Dobra). El cordal cuarcítico que limita este valle por el Sur (Cuesta Fría), no presenta restos glaciares. No hay bloques calizos que pudieran ser interpretados como erráticos ni formaciones superficiales que contengan otro tipo de materiales que no sean los autóctonos. De 
la Horcada Salambre hacia el Sur tampoco hay ningún vestigio glaciar, por lo que la lengua que descendió por la Canal del Perro no desbordó esta horcada ni el cordal citado por ningún punto, sino que se canalizó valle abajo hacia el WNW por la riega de la Vareda.

Los materiales morrénicos más bajos que se han localizado en dicho valle están a $1.440 \mathrm{~m}$ de altitud, conformando el extremo más bajo de un cordón morrénico achatado y adosado a un promontorio labrado sobre pizarras, sobre el que se han encajado surcos de arroyada a derecha e izquierda. De todas formas, la presencia de rocas con el pulido glaciar característico, así como la propia morfología del valle, sugieren que la lengua glaciar descendió hasta una altitud menor, probablemente cercana a la confluencia con el Dobra. Más arriba, hacia la Canal del Perro, se conserva un cierre morrénico abierto en su centro que marca otro avance menor o pequeña estabilización posterior de la difluencia estudiada.

\subsubsection{Los glaciares del borde meridio-} nal del macizo: Llos, Pambuches, Arestas y los Moledizos

El glaciar de los Moledizos. Se trata de un pequeño glaciar de lengua incipiente alojado al Suroeste de la cumbre de los Moledizos. Una loma morrénica de escaso desarrollo situada al Oeste del Collado Jover marca su límite oriental (González-Trueba y Serrano, 2011).

El glaciar de Llos. El glaciar de Llos emitió dos lenguas separadas por un resalte rocoso existente entre medias. El límite más oriental del glaciar viene marcado por una morrena lateral que desciende desde el área de la Loma de la Flor hasta las cercanías del Joro Berín, donde queda interrumpida por una capa cuarcítica en resalte, para conti- nuar más abajo hasta las inmediaciones del invernal de Argoya. En este lugar hay otra morrena de pequeñas dimensiones que hace de cierre por el W, dibujando entre ambas de forma nítida la caja glaciar y situando el frente de la lengua más oriental a $1.160 \mathrm{~m}$. Al interior del cordón morrénico descrito en primer lugar hay otras dos morrenas de menores dimensiones y disposición ligeramente arqueada localizadas a $1.260 \mathrm{~m}$ aproximadamente. Más hacia el Oeste hay otro cordón morrénico adosado a un interfluvio cuarcítico que asciende por la vertiente izquierda de la Riega de Miradorio hasta casi enlazar con la morrena más externa de las dos que hay en la Vega de Llos, dibujando el borde oriental de la segunda lengua emitida por este glaciar. Su frente, al igual que en el caso anterior, se sitúa a $1.160 \mathrm{~m}$ de altitud (Figura 1). No existen más evidencias glaciares por debajo de los frentes mencionados. Tal sólo cabe citar la existencia de algunos bloques de caliza situados por delante del frente más oriental, junto con cantos y abundantes gravas en ocasiones cementadas por carbonato cálcico; estos últimos materiales los interpretamos como depósitos proglaciares.

El glaciar de Pambuches. Fue un aparato de cierta entidad y bien alimentado, al generarse a los pies de algunas de las cimas más altas del Macizo del Cornión (Torre Bermeja, 2.400 m; Pardo Pescuezo, $2.302 \mathrm{~m}$ ), y también a favor de depresiones kársticas preexistentes (Hoyos Llerosos), que constituyeron enclaves muy favorables para la acumulación de nieve y su transformación en hielo. Parte de la masa de este glaciar saltó por el escarpe existente entre el Collado Verde y el de Pambuches, en el que se conservan numerosas rocas aborregadas, para emitir una lengua que descendió hasta $1.060 \mathrm{~m}$ 
de altitud y generó un complejo morrénico en las Praderas de Hoyobladas integrado por sendos cordones laterales, uno de ellos desdoblado. Otra parte del glaciar descendió desde la cubeta glaciokárstica de los Hoyos Llerosos hacia las Lleras de Pambuches a través de un nuevo escarpe (Sedos de la Cabra Blanca). En las Lleras depositó un complejo morrénico con el frente situado a $1.740 \mathrm{~m}$, integrado por un arco externo de mayor desarrollo y otros dos internos de menor envergadura, evidenciando una fase menor de estabilización ya dentro del retroceso, pero todavía con el desarrollo suficiente para saltar el escarpe mencionado anteriormente y depositar el conjunto morrénico descrito a sus pies. En su fase de máximo desarrollo el glaciar paso a través del collado abierto entre los Picos de Pambuches $(1.912 \mathrm{~m})$ y la Pandona (1.792 m), en el que se han identificado bloques erráticos, generando otra lengua que depositó un nuevo complejo morrénico en torno a Pantivalles con el frente situado a $1.080 \mathrm{~m}$ de altitud. El complejo cuenta con dos morrenas laterales en ocasiones bastante desdibujadas, así como un pequeño arco frontal interno a
$1.130 \mathrm{~m}$, que atestigua una estabilización de la lengua con posterioridad a su máximo avance. Una tercera lengua descendió por el Vallejón de las Horcadas, generando unos cordones morrénicos muy voluminosos y bien conservados que señalan el descenso del glaciar hasta $940 \mathrm{~m}$ de altitud (Figura 10A y 10B). Existió otra difluencia menor del glaciar de Pambuches hacia el Sur del Collado Verde que depositó dos morrenas laterales mucho menos voluminosas que en los otros casos. La más oriental de ellas está afectada por un deslizamiento traslacional que movilizó gran parte de su masa. Cabe citar, por último, la existencia de transfluencias entre el glaciar de Pambuches y el de Carombo-Capozo a través de la Horcada Ancha (entre la Torre Bermeja y Pardo Pescuezo), por otro collado justo al Este de Pardo Pescuezo, y por una tercera escotadura al Norte de la Torre de Ita.

El glaciar de Arestas. Fue un aparato alpino alimentado por un único circo. Depositó sendas morrenas laterales (la más occidental desdoblada) que descendieron hasta $1.020 \mathrm{~m}$ de altitud, junto a otras menores internas y un arco morrénico frontal elevado a $1.170 \mathrm{~m}$ (Figura 1).
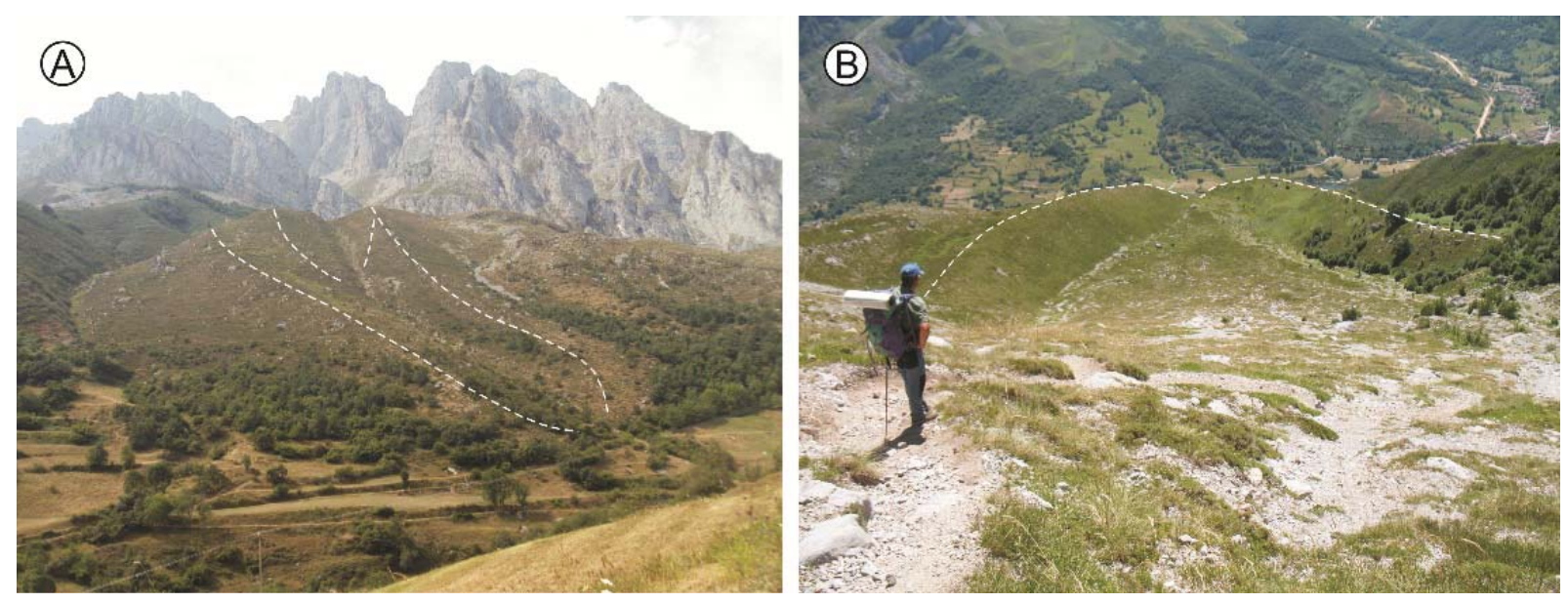

Fig. 10. (A) Detalle del sector frontal del complejo morrénico del Vallejón de las Horcadas, y (B) de su sector interno, en el que se diferencian netamente dos cordones morrénicos laterales. 


\subsubsection{Fases glaciares}

Como se desprende del análisis de los testimonios morfológicos descritos, durante la Última Glaciación el Macizo del Cornión estuvo ocupado en gran medida por el hielo, responsable de la construcción de numerosos y extensos complejos morrénicos, diferenciándose claramente, no obstante, dos fases morfogenéticas principales que pasaremos a detallar.

\subsubsection{Fase de Máxima Extensión del} Hielo (I)

Durante esta fase el Cornión constituía un domo glaciar, un campo de hielo integrado por 8 glaciares diferentes del que solamente sobresaldrían algunas pequeñas crestas rocosas a modo de nunataks (Figura 11). La extensión de este domo fue de 7.329,8 ha (Ruiz-Fernández et al., 2016b; Tabla 2). En este momento los glaciares alcanzaron su máxima expansión, con los frentes situados a las altitudes más bajas (entre 550 y $1.480 \mathrm{~m}$ ), y se edificaron los complejos morrénicos más importantes $\mathrm{y}$ voluminosos del macizo, bien representados en la parte Norte en torno a Pandecarmen, los lagos Enol y Ercina, Belbín, Espines, Parres, Arnaedo, Vega Maor y Ostón. En las gargantas que descienden hacia el Cares destacan las morrenas laterales de las Vegas, y especialmente la voluminosa morrena lateral izquierda, que alcanza prácticamente el nivel del río Cares. Hacia el Dobra esta fase estaría representada por los restos morrénicos alojados a los pies de las Canales de Ozania y Carombo, mientras que en el escarpe meridional del Cornión sobresalen los complejos morrénicos de Llos, Hoyobladas, Vallejón de las Horcadas y Arestas, algunos de ellos verdaderamente voluminosos y bien conservados.

Tabla 2. Número de glaciares, superficie glaciada total, superficie media por glaciar y rango altitudinal de los frentes, en cada una de las cuatro grandes fases glaciares identificadas en el Macizo del Cornión.

\begin{tabular}{|c|c|c|c|c|}
\hline Fase glaciar & $\begin{array}{c}\text { Número de } \\
\text { glaciares }\end{array}$ & $\begin{array}{c}\text { Superficie } \\
\text { glaciada total } \\
\text { (ha) }\end{array}$ & $\begin{array}{c}\text { Superficie media } \\
\text { por glaciar } \\
\text { (ha) }\end{array}$ & $\begin{array}{c}\text { Rango altitudinal de los } \\
\text { frentes } \\
\text { glaciares } \\
\text { (m) }\end{array}$ \\
\hline $\begin{array}{c}\text { Máxima Extensión } \\
\text { del Hielo (I) }\end{array}$ & 8 & $7.329,8$ & 916,2 & $550-1.480$ \\
\hline Interna (II) & 8 & $5.842,9$ & 730,4 & $1.000-1.775$ \\
\hline $\begin{array}{c}\text { Glaciares de altitud } \\
\text { (III) }\end{array}$ & 37 & 797,4 & 21,6 & $1.840-2.100$ \\
\hline $\begin{array}{c}\text { Glaciares de fondo de } \\
\text { circo (IV) }\end{array}$ & 3 & 10 & 3,3 & $2.200-2.230$ \\
\hline
\end{tabular}

Con el objetivo de obtener una aproximación cronológica para esta fase glaciar, se efectuaron dos sondeos en la majada de Belbín de $1,82 \mathrm{~m}$ y $5,4 \mathrm{~m}$ de profundidad. De muro a techo, en ambos se distingue un primer nivel de materiales arcillosos con pequeñas gravas calcáreas aristadas al que atribuimos un origen periglaciar, que alcanza un espesor de unos 2,20 m en el sondeo más profundo, otro nivel de 60 a $260 \mathrm{~cm}$ de arcillas de tonos grises de origen lacustre, así como un tercer nivel de 40-60 cm 
de potencia con alto contenido orgánico e intercalación de carbones (Nieuwendam et al., 2016; Fernández et al., 2016a, 2016b). En el sondeo más largo se han datado por AMS dos muestras cuyos resultados son de $36.718 \pm 1.203$ años cal BP a $539 \mathrm{~m}$ de profundidad y de $27.363 \pm 425$ años cal BP a $357 \mathrm{~cm}$ (Tabla 1). El dato cronológico más antiguo constituye una edad mínima para la fase de MEH dentro de la Última Glaciación, que concuerda perfectamente con los datos cronológicos obtenidos en la base de los sondeos estudiados en el Lago Enol por Moreno et al. (2010) y en Comeya por Jiménez y Farias (2002) y Jiménez et al. (2013). En el primer caso sitúan la fase de MEH del glaciar de Enol con anterioridad a $38 \mathrm{ka} \mathrm{cal}$ $\mathrm{BP}$, mientras que los dos últimos estudios proporcionaron edades comprendidas entre 45 y 43 ka para los depósitos proglaciares de la depresión de Comeya sincrónicos a la MEH. En los Puertos de Áliva, situados entre los macizos Central y Oriental de los Picos de Europa, Serrano et al. (2012, 2013) obtuvieron una edad anterior a 35.7-34.8 ka cal BP. Por su parte, en otros macizos cantábricos las cronologías para la MEH oscilan entre 45 y 36 ka (MIS 3) (Pellitero, 2013; Serrano et al., 2013; Rodríguez-Rodríguez et al., 2015). No obstante, se están obteniendo edades incluso anteriores, que indican la existencia de fases glaciares previas (78-65 ka, MIS 4; Frochoso et al., 2013; RodríguezRodríguez et al., 2016). En cualquier caso, las edades absolutas relacionadas con la MEH en las Montañas Cantábricas preceden claramente al UMGG, responsable en cambio de la máxima expansión del gran indlansis escandinavo hace unos 20 a $18 \mathrm{ka}$ cal BP (García-Ruiz et al., 2010). En otros ámbitos ibéricos como las Montañas de Noroeste la $\mathrm{MEH}$ es anterior a $30 \mathrm{ka}$ cal BP (Pérez-Alberti et al., 2011), tal y como también sucede entre 32 y 30 ka (Gómez-Ortiz et al., 2012). En los Pirineos los depósitos de origen glaciar datados mediante C14 y OSL sugieren igualmente una $\mathrm{MEH}$ anterior al UMGG (García-Ruiz et al., 2003, 2012; González-Sampériz et al., 2006; Jiménez et al., 2013), mientras que el uso de técnicas de datación por isótopos cosmogénicos ofrece resultados mucho más próximos e incluso sincrónicos con el UMGG, comprendidos entre 26 y 23 ka (Pallàs et al., 2006; Delmas et al., 2008; García-Ruiz et al., 2014; Palacios et al., 2015). En este mismo sentido, en el Sistema Central la cronología de la $\mathrm{MEH}$ coincide igualmente con el UMGG (Palacios et al., 2011, 2012a, b).

Esta descoordinación temporal de la MEH entre los diferentes macizos montañosos ibéricos podría deberse a la dinámica atmosférica imperante durante el último ciclo glaciar, que propició diferencias climáticas a escala regional, y también a una mayor sensibilidad y rápida respuesta de los pequeños glaciares de montaña a los cambios acontecidos durante el Pleistoceno superior (Florineth y Schlüter, 2000; Kuhlemann et al., 2008; García-Ruiz et al., 2013). Sin embargo, no debemos olvidar la incertidumbre provocada por el uso de diferentes sistemas de datación (García-Ruiz et al., 2010; Jiménez et al., 2013). 

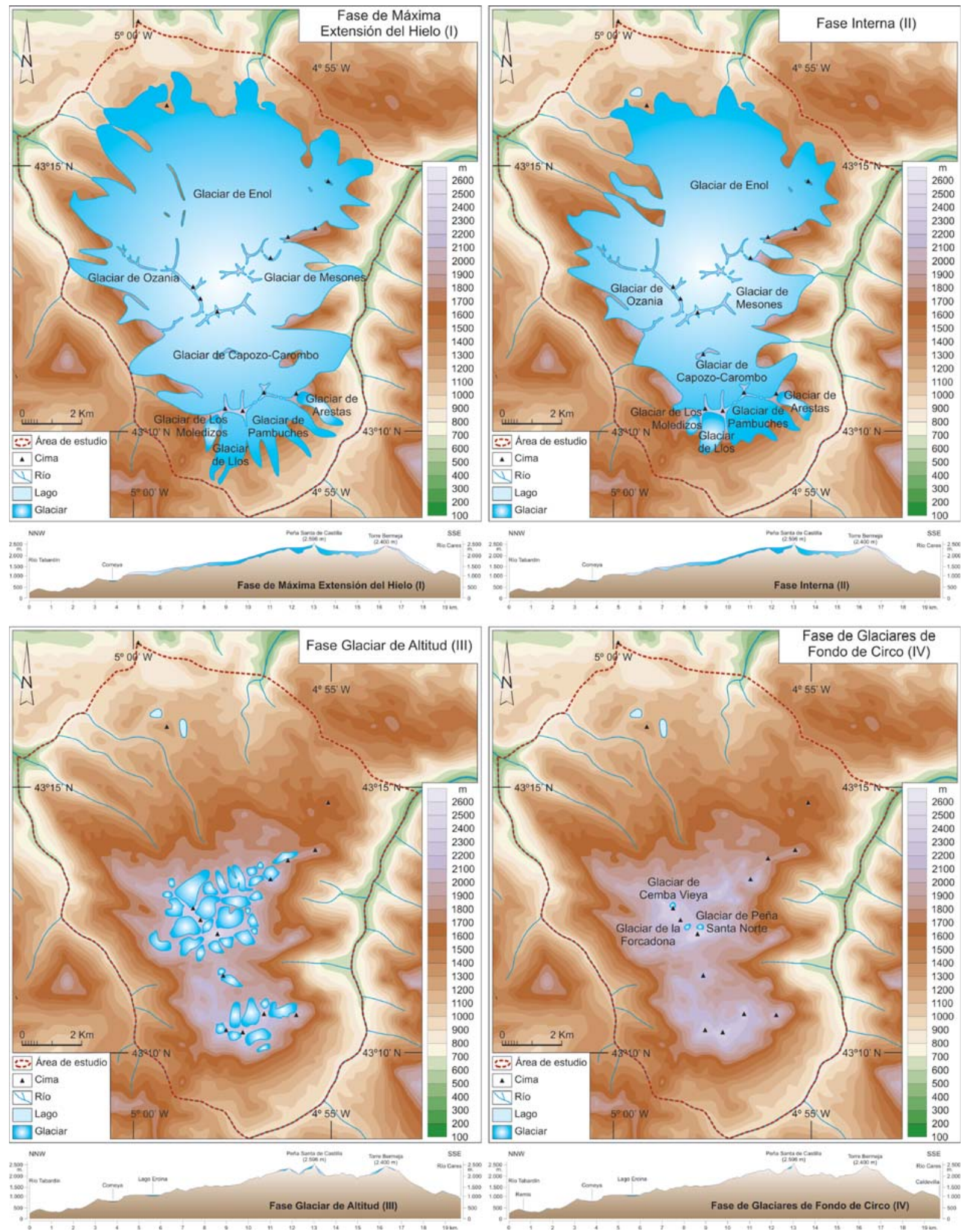

Fig. 11. Grandes fases glaciares identificadas en el Macizo del Cornión. Arriba a la izquierda Fase de Máxima Extensión del Hielo (I), arriba a la derecha Fase Interna (II), abajo a la izquierda Fase Glaciar de Altitud (III), y abajo a la derecha Fase de Glaciares de Fondo de Circo (IV). 


\subsubsection{Fase Interna (II)}

Se trata de una fase de estabilización y empuje generadora de nuevos depósitos glaciares, que acontece una vez que ya se ha iniciado el retroceso glaciar tras la $\mathrm{MEH}$, y antes de que se produzca la deglaciación generalizada del macizo hasta los pies de las principales cumbres, donde se encuentran los siguientes complejos morrénicos de entidad. En efecto, al interior de los complejos morrénicos mayores, atribuidos al máximo avance glaciar, se encuentran morrenas en forma de arcos y cordones de menor entidad y en ocasiones separadas de éstos varios centenares de metros, que evidencian unas masas de hielo de menor espesor y capacidad modeladora, aunque con una extensión todavía importante, que alcanzó en conjunto 5.842,9 ha de extensión (Tabla 2), repartidas en 8 aparatos glaciares como en el caso anterior (Figura 11). A esta etapa corresponden, entre otros, el pequeño arco existente en la Vega de Enol, las morrenas laterales que flanquean la cabecera del río del Osu (entre la Vega de Enol y la Vega la Cueva), así como las generadas en la Redondiella, las Bobias, la Vega del Ceñal y la Vega de Llos (Figura 1).

Este nuevo episodio de avance durante la Última Glaciación está ampliamente representado en el resto de los macizos cantábricos que estuvieron glaciados, aconteciendo varios milenios después de la Fase de MEH (García de Celis, 1997; Frochoso y Castañon, 1998; González-Gutiérrez, 2002; Jiménez y Farías, 2002; González-Trueba, 2007a; Pellitero, 2013; Serrano et al., 2012, 2013; Frochoso et al., 2013; Rodríguez-Rodríguez et al., 2015). Con el objeto de aportar también una edad mínima para esta segunda fase glaciar, se realizó un tercer sondeo en la Vega del Bricial, depresión glaciokárstica localizada al interior de un complejo morrénico atribuido a la Fase Interna (Finiglaciar, según la terminología clásica). Se consiguió profundizar hasta $8 \mathrm{~m}$ en un depósito de turba, aunque en este caso no se llegó hasta el sustrato, recogiéndose muestras para datar por $\mathrm{C} 14$ a 8 y $2,80 \mathrm{~m}$ de profundidad. Las edades obtenidas fueron $11.150 \pm 900$ años cal BP y 3.675 235 años cal BP respectivamente (Tabla 1). Por tanto, la edad más antigua representa una cronología mínima para la Fase Glaciar Interna. En este sentido, las edades obtenidas en diversos sectores de la Cordillera Cantábrica como Redes o los propios Picos de Europa para este segundo período de avance glaciar, logradas mediante la datación directa de depósitos glaciares, o bien inferidas a partir del estudio de secuencias sedimentarias, oscilan entre 23 y $19 \mathrm{ka}$, por lo que dicho avance es contemporáneo al UMGG (MIS 2) (Jiménez y Farias, 2002; Jiménez et al., 2013; Pellitero, 2013; Serrano et al., 2012, 2013; Rodríguez-Rodríguez et al., 2015). También ha sido detectada otra fase de avance glaciar entre 23-17 ka en otras áreas montañosas de la Península Ibérica como los Pirineos (Pallàs et al., 2006; Delmas et al., 2008, 2011; Palacios et al., 2015), el Sistema Central (Palacios et al., 2012a, 2012b; Carrasco et al., 2013; Domínguez-Villar et al., 2013) y Sierra Nevada (Gómez-Ortiz et al., 2012; Oliva et al., 2014).

\subsection{Fase Glaciar de Altitud (III)}

Las huellas glaciares que se conservan en la alta montaña, especialmente los complejos morrénicos depositados a los pies de los grupos de cumbres más importantes, permiten reconstruir con bastante precisión los límites de 37 pequeños glaciares generados 
en orientaciones diversas, aunque con un claro predominio de las Norte, que ocuparon una extensión total de 797,4 ha (Tabla 2; Figura 11). Estos glaciares pertenecen a una etapa de avance glaciar menor que acontece una vez que la mayor parte del Macizo del Cornión ya está libre de hielos, y por tanto circunscrita a los sectores más elevados, a favor de cumbres de paredes verticales de gran desarrollo que aseguraron una buena acumulación nival y una sobrealimentación por aludes, además de proteger a muchas de las masas de hielo de la insolación.

\subsubsection{Testimonios morfológicos y recons- trucción glaciar}

Se trata mayoritariamente de aparatos de circo, si bien algunos emitieron incluso cortas lenguas. A continuación, se reconstruirán los principales glaciares generados en esta fase a partir de las evidencias morfológicas y sedimentarias conservadas. Uno de los complejos morrénicos más importantes de esta fase es el de las Barrastrosas, depositado por el glaciar generado en la cara Norte de la Torre Santa María de Enol, muy pulsador y ya de cierta envergadura, capaz de emitir una corta lengua (Figuras 1 y 12). El material morrénico se extiende con alguna interrupción desde $2.150 \mathrm{~m}$ de altitud hasta $1950 \mathrm{~m}$, conformando un gran manto en el que aparecen intercalados hasta 12 arcos morrénicos (Figura 13A). El más externo es el de mayor desarrollo. En la vertiente Sur de la Torrezuela, el Jou las Pozas estuvo ocupado por otro glaciar, responsable de la deposición de un arco simple a $2.060 \mathrm{~m}$. La estructura sedimentaria del mismo es la típica del till, estando colonizado incipientemente por la vegetación. Más al Este cabe citar el complejo morrénico de la Boca de Corroble, en el que se diferencian claramen- te tres arcos morrénicos en el sector frontal. El frente de este glaciar se situó a $1.960 \mathrm{~m}$ de altitud.

En la Llerona se generó un glaciar orientado al SE. El fondo del jou homónimo está ocupado por un complejo morrénico en el que, junto a una voluminosa acumulación de cantos y bloques, cabe citar la existencia de una pequeña loma que ocupa el extremo Oeste de la depresión glaciokárstica, emplazándose a $1.975 \mathrm{~m}$ de altitud. A continuación, se conserva otra morrena poco marcada a $1.985 \mathrm{~m}$ que separa la cubeta anterior del jou situado justo al Sur. En una posición más externa destaca un arco que se alza en el borde meridional del segundo jou citado, y finalmente más al Sur hay bloques erráticos, así como material morrénico de escasa potencia que dibuja un arco incipiente. Por su parte, el complejo morrénico del Gato, situado justo al SE de la Llerona, está constituido por dos arcos frontales ubicados a 1940 y 1954 m, así como por otro arco más interno y desconectado de los anteriores, en cuyo interior se desarrolló ulteriormente un glaciar rocoso. Más al SE, en la ladera Norte de las Torres de Cotalbín $(2.187 \mathrm{~m})$ se generó un glaciar de circo que emitió un modesto complejo morrénico.

Los testimonios sedimentarios que se conservan en la vertiente Sur de Peña Santa de Castilla permiten reconstruir tres glaciares. El más occidental, situado a los pies de la Aguja José del Prado, prácticamente no ha dejado testimonios morfológicos. El situado en una posición central está constituido por dos arcos contiguos, siendo el interno muy marcado, mientras que el externo es menos nítido y discontinuo, desdoblándose hacia el Este en dos. Más hacia el Este destaca un gran amasijo de cantos y bloques (en ocasiones de tamaños métricos) ubicado a los pies 


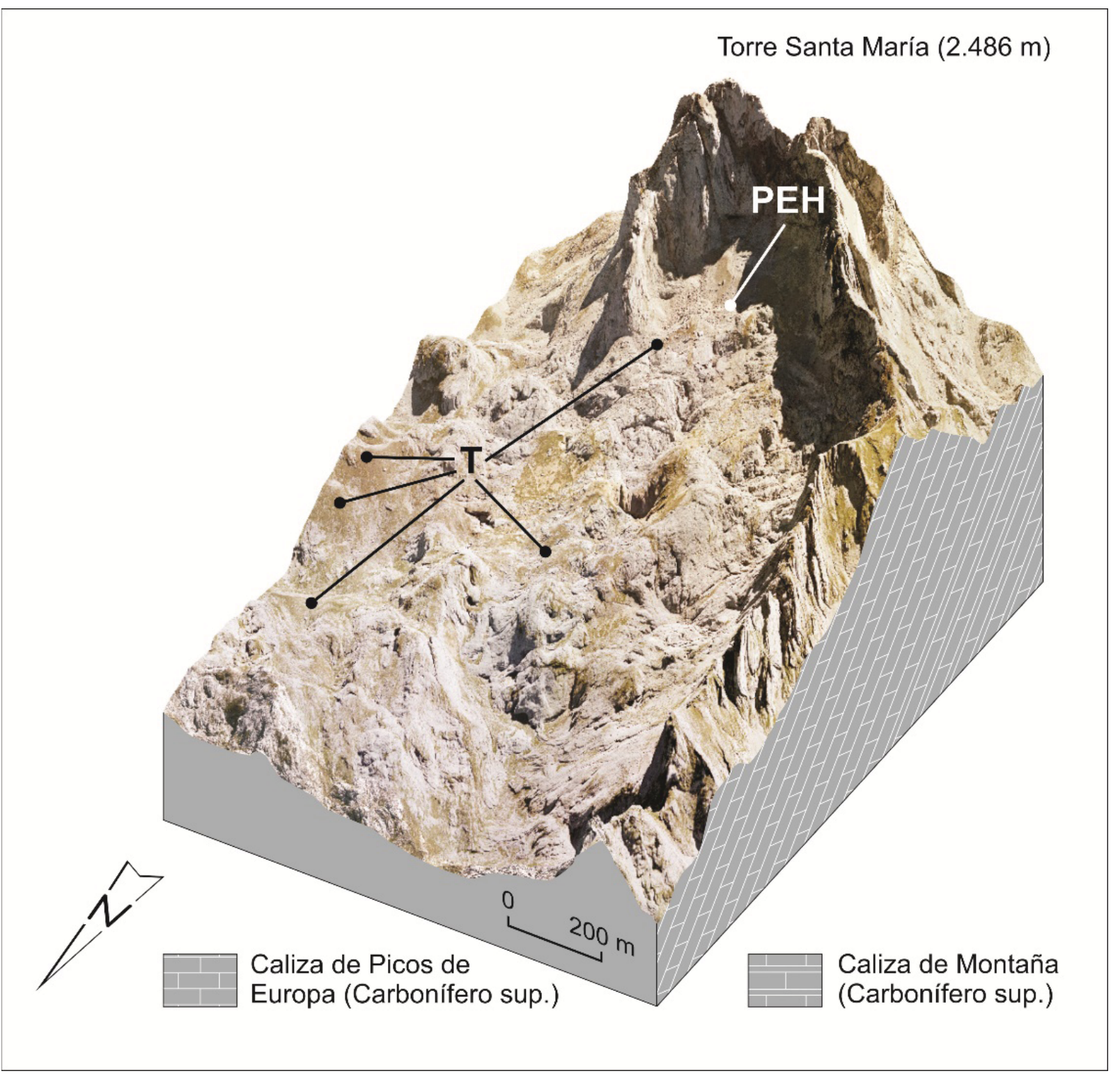

Fig. 12. Bloque-diagrama del área de las Barrastrosas y Cemba Vieya. El circo glaciar de Cemba Vieya, excavado en la cara Norte de una de las cimas más altas del Cornión (la Torre Santa María de Enol, con 2.486 m de altitud), y expuesto en la primera línea de cumbres del macizo a los vientos húmedos y los frentes provenientes del W y del NW, cuenta con un importante complejo morrénico perteneciente a la Fase Glaciar de Altitud (T) en el que se diferencian claramente dos conjuntos de morrenas claramente separadas desde el punto de vista espacial; uno de máximo avance muy pulsador, responsable de la emisión de una corta lengua, y otro de acantonamiento del hielo a los pies del circo. En una posición más retranqueada se conserva un arco morrénico perteneciente a la $\mathrm{PEH}$, que será tratado en apartados posteriores 

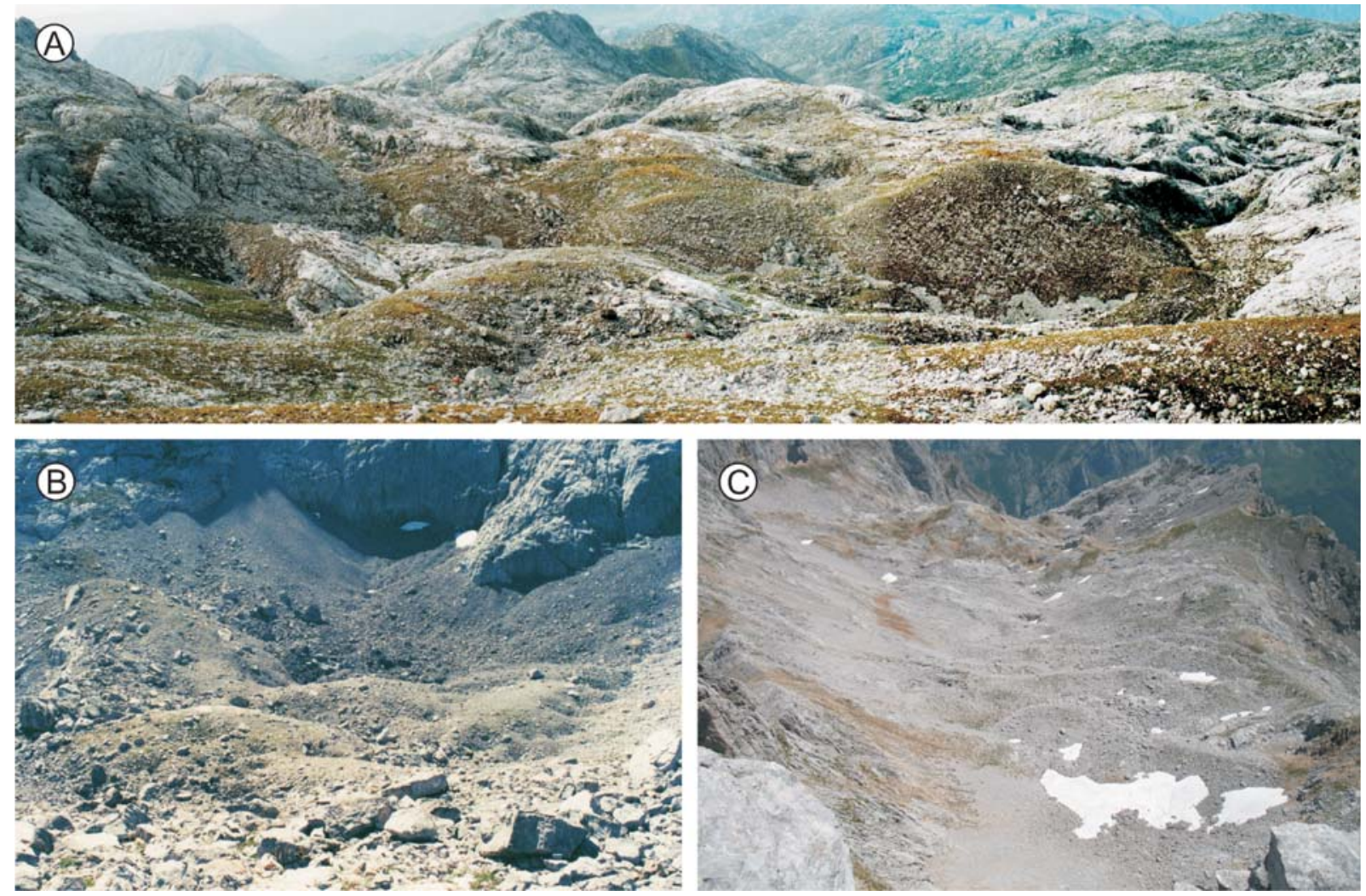

Fig. 13. Ejemplos de complejos morrénicos depositados durante la Fase Glaciar de Altitud. (A) las Barrastrosas, (B) Peña Santa de Castilla Norte, y (C) Hoyos Llerosos.

de la Brecha de los Cazadores. En principio la citada formación podría ser confundida con un glaciar rocoso. Sin embargo, carece de arcos o surcos que denoten el flujo de la masa salvo en su mitad oriental, donde aparecen algunas estructuras poco definidas que evocan un flujo. No obstante, el depósito no dispone del frente abultado característico de los glaciares rocosos relictos, aunque desde cierta distancia pudiera parecer que es así, ya que la zona distal reposa sobre un afloramiento rocoso en resalte; y su raíz está claramente desconectada de las pedreras que recubren la ladera del fondo del circo. Además, el sustrato rocoso aflora en numerosas partes, y muy especialmente en el área central, partiendo prácticamente la citada formación en dos cuerpos; mientras que en otros sectores se trata simplemente de un recubrimiento pelicular de bloques y cantos. Por ello, interpretamos esta formación como material morrénico perteneciente a un glaciar negro, cuyo frente se situó a $1.891 \mathrm{~m}$ s.n.m.

En el recuenco excavado al Norte de la Cerra del Rayo (2.078 m), situada en el extremo suroriental del cordal de Peña Santa de Castilla, existió otro glaciar de circo que generó una única morrena a $1.995 \mathrm{~m}$ de altitud. Justo al Norte de este último, en el área de los Basares, se depositó a 2.000 m s.n.m. un complejo morrénico de mucha mayor entidad que el anterior, integrado por dos arcos. En torno al Jou Santo cabe citar otros complejos morrénicos pertenecientes a la fase glaciar de altitud, como los existentes al $\mathrm{N}$ de la Forcadona y de Peña Santa de Castilla. El segundo de ellos se 
eleva a $1.930 \mathrm{~m}$ sobre el fondo del citado jou, y está constituido por sucesivos arcos con boches entre medias (Figura 13B). Sobre un umbral ubicado en una posición más retranqueada se conservan otras morrenas. En la cara $\mathrm{N}$ de Piedralengua existió otro glaciar de circo que depositó un arco morrénico a $2.000 \mathrm{~m}$ de altitud sobre un umbral de disposición arqueada. Justo al Norte, al amparo de la vertiente Este del Porru la Capilla $(2.267 \mathrm{~m})$ y SE de las Torres de los Cabrones (2.270 m), se formó otro glaciar de circo que generó un complejo morrénico de mayor entidad que el anterior.

En vertiente de umbría de la Robliza (2.227 m) y Peña Blanca (2.204 m) destaca un complejo morrénico compuesto por un arco situado a $1.845 \mathrm{~m}$ de altitud, seguido de una acumulación de material morrénico sin forma definida salpicada de boches, y otro arco dispuesto a $1.880 \mathrm{~m}$. Este complejo está precedido por otros dos arcos morrénicos que se alzan a 1.770 y $1.775 \mathrm{~m}$ de altitud en el extremo del Joón de Oliseda más cercano a la Horcada Arenizas, por tanto, claramente desconectados de los anteriores, por lo que los interpretamos como pertenecientes a una fase glaciar previa. Por su parte, en el interior del circo de las Torres de los Cabrones - Punta Gregoriana (2.260 m), se conserva un complejo morrénico compuesto por un arco frontal de planta festoneada que está desdoblado en su parte más occidental. En el circo de orientación Norte definido por las cumbres de los Moledizos (2.2.95 m) y la Torre Bermeja $(2.400 \mathrm{~m})$ se formó un aparato glaciar de $\sim 650 \mathrm{~m}$ de longitud por 300-400 $\mathrm{m}$ de anchura, que depositó un voluminoso arco morrénico frontal a $2.015 \mathrm{~m}$ de altitud.

Más al Norte, el fondo de la cubeta glaciokárstica de los Hoyos del Caballo está recubierta por material morrénico remodelado por numerosos boches. Por su parte, el circo delimitado por la Torre Bermeja, Pardo Pescuezo (2.302 m) y la Torre Parda ( $2.315 \mathrm{~m})$ cobijó otro glaciar que emitió una corta lengua responsable de la formación de un arco morrénico principal a $2.020 \mathrm{~m}$, desdoblado en tres hacia el Este, y seguido de otro arco menor situado en una posición más interna y también desdoblado. Más hacia el interior, desconectado por completo de los anteriores y a una altitud de $2.035 \mathrm{~m}$, hay otro arco desdibujado y apoyado parcialmente sobre un resalte estructural. Finalmente, a $2.040 \mathrm{~m}$ se encuentra un último arco, de escasa entidad, que enlaza con una morrena lateral perteneciente a la pulsación descrita anteriormente. Ese último arco y el material morrénico informe existente a su misma altura, pero más al Este, evidencia que antes de desaparecer definitivamente, la primitiva masa glaciar llegó a escindirse en dos pequeños cuerpos helados alojados en el fondo del circo y separados por un afloramiento calizo en resalte interpuesto entre medias. Al amparo de la sombra proporcionada por el contrafuerte septentrional de la Torre Parda se formó otra pequeña masa glaciar que dejó una morrena de disposición arqueada a $1.985 \mathrm{~m}$.

Al Sur del grupo de cimas citadas anteriormente, en el área de los Hoyos Llerosos, se generó un glaciar de circo que depositó un voluminoso complejo morrénico integrado por al menos cinco arcos, además de abundante material informe salpicado de boches (Figura 13C). Su frente se situó a $2.120 \mathrm{~m}$ de altitud. Por su parte, al Oeste del Collado de Pambuches existió otro pequeño aparato glaciar de orientación Sur y frente a 1.900 $\mathrm{m}$, al amparo de paredes de cierto desarrollo $(2.190 \mathrm{~m})$, muy verticales y con importante 
alimentación por aludes. En el extremo NW del amplio circo comprendido entre la Torre Parda, la Torre de Ita, la Torre Ciega y las Torres de Arestas, queda individualizado un pequeño recuenco separado del resto del circo por un espolón rocoso, a cuyos pies se depositaron dos arcos morrénicos frontales a $2.020 \mathrm{~m}$ de altitud que reposan sobre la cara interna de un umbral. Por su parte, en el extremo Sureste se depositó un arco frontal muy marcado y otro más interno de menor entidad, ambos elevados a $2.070 \mathrm{~m}$. Más abajo, a $1.936 \mathrm{~m}$, hay material morrénico sin forma definida rellenando el fondo de una depresión glaciokárstica y, tras superar un pequeño umbral, se conservan otras dos morenas achatadas y de escasa entidad que dibujan un cierre elevado a 1.900 m s.n.m. Todo el conjunto descrito conformó un único glaciar posteriormente dividido en dos masas menores.

\subsubsection{Dinámica glaciar y aproximación cronológica}

Como se desprende de las evidencias morfológicas descritas, en su mayor parte los glaciares generados durante esta fase fueron pequeños aparatos de circo. Solamente algunos de ellos fueron capaces de emitir cortas lenguas, como los de las Barrastrosas, Hoyos Cabaos, los Moledizos - Torre Bermeja y Peña Santa Norte. En este sentido, es necesario mencionar un comportamiento diferenciado en función de la orientación, pues los glaciares de componente Norte (54,3\% del total) tuvieron una mejor alimentación nival y una menor incidencia de la radiación que los orientados al Sur (20\%), lo que se tradujo en un mayor desarrollo de los primeros, como se puede observar si se compara la diferente envergadura alcanzada por los glaciares de las caras Norte y Sur de Peña Santa de Castilla, o los generados en la umbría y la solana del grupo de cumbres dominado por la Torre Bermeja.

Asimismo, en el apartado anterior quedó patente que muchos de los glaciares de esta fase (aquellos con unas condiciones topoclimáticas menos favorables) solamente fueron capaces de edificar un único arco morrénico (es el caso, por ejemplo, del formado al $\mathrm{N}$ de la Cerra del Rayo), mientras que otros generaron varios arcos sucesivos que no implicarían variaciones sustanciales en la superficie de los mismos (los Basares, Corroble, etc.); $\mathrm{y}$ finalmente hay otros aparatos glaciares que han sido capaces de depositar incluso dos conjuntos morrénicos integrados por un número variable de arcos y claramente separados desde el punto de vista espacial y también con cierta diferencia altitudinal entre ambos (Peña Santa Norte, las Barrastrosas, glaciares de la vertiente $\mathrm{N}$ de la Torre Bermeja, etc.).

Normalmente la morrena más externa, que señala la máxima expansión glaciar, es bastante más voluminosa que las restantes. Estos restos ponen en evidencia la sucesión de dos episodios claramente diferenciados dentro de la fase glaciar de altitud. En el Macizo de los Urrieles González-Trueba (2007a) señaló también la diferenciación de dos episodios dentro de esta etapa al conservarse testimonios sedimentarios similares a los aquí descritos. Por otro lado, cabe destacar el importante retoque nival que muestran muchas de las morrenas atribuibles a esta etapa, especialmente las situadas en posiciones más retranqueadas en el interior de los circos.

No ha sido posible obtener dataciones absolutas de depósitos directamente relacionados con la fase glaciar de altitud. Si bien han sido descritas huellas glaciares análo- 
gas a las presentes en el Cornión para esta fase en otros ámbitos de alta montaña de la Cordillera Cantábrica, como los macizos Central y Oriental de los Picos de Europa, Fuentes Carrionas, el Macizo de las Ubiñas, la Sierra de Cebolleda, Alto CampoValdecebollas y el Alto Nalón (Jiménez, 1996; González- Trueba, 2007a; Pellitero, 2013; Serrano et al., 2012, 2013; Gallinar et al., 2014), por el momento tampoco hay edades absolutas y, por lo tanto, su cronología sigue siendo incierta. Sin embargo, el estudio de los registros sedimentarios obtenidos en el lago Enol por Moreno et al. (2010) evidenció la existencia de una fase fría y seca durante el Younger Dryas (13,5 a 11,6 ka cal BP), que puede corresponder a esta tercera fase de expansión glaciar. Los sedimentos del paleolago de Campo Mayor, situado entre los macizos Central y Oriental de los Picos de Europa, indican igualmente una tendencia de enfriamiento del clima hacia el Holoceno que comienza a partir de 13,9 ka cal BP (Serrano et al., 2012). Por lo tanto, este avance glaciar se puede atribuir al periodo Tardiglaciar (Late Glacial; Ehlers et al., 2006).

Las formas y depósitos glaciares atribuidos a esta fase abundan también en otros macizos montañosos ibéricos (Pirineos, Sierra Nevada, Gredos, Guadarrama; GarcíaRuiz et al., 2014, 2018; Oliva et al., 2014), si bien los glaciares generados no tuvieron la extensión y complejidad propia de otros conjuntos montañosos europeos como los Alpes (Ivy-Ochs et al., 2008).

\subsection{Fase de glaciares de fondo de circo o IV (PEH).}

Durante la PEH se generaron tres pequeños glaciares en el Macizo del Cornión a favor de los grupos de cumbres más elevados, siempre a resguardo de la insolación y en relación con una abundante sobrealimentación por aludes (González- Trueba, 2005 y 2007b). Se trata de los glaciares de Cemba Vieya, Peña Santa de Castilla y la Forcadona (Figuras 1 y 11). La extensión máxima ocupada por estos glaciares fue de 10 ha (Tabla 2). Las formas erosivas y sedimentarias que dejaron están muy bien conservadas. Las morrenas carecen por completo de vegetación y procesos edáficos. El pulido glaciar es fresquísimo y se conservan perfectamente las estrías (Figura 4A, 4B y 4C), ya que las superficies rocosas prácticamente no están retocadas por la karstificación. En cambio, las morrenas tardiglaciares, localizadas a menor cota, suelen estar ligeramente colonizadas por vegetación herbácea, excepto las que están situadas en posiciones más retranqueadas en el interior de los circos más altos. Salvo excepciones, en este caso las estrías ya no se conservan. Han sido borradas por la disolución superficial de la caliza, que a escala de detalle ha eliminado el pulido glaciar típico, dándole a la superficie rocosa un aspecto mucho más áspero y rugoso.

Las evidencias morfológicas citadas en el párrafo anterior, la conservación de un helero enterrado y de neveros permanentes/ semipermanentes en la parte interna de los complejos morrénicos, que en algunos casos llegan a enlazar directamente con ellos, así como los testimonios históricos existentes, estudiados en profundidad por GonzálezTrueba (2005 y 2007b), permiten atribuir los citados glaciares a la PEH.

El glaciar de Cemba Vieya, alojado en el interior de un circo de orientación Norte y paredes subverticales culminado por la Torre Santa María de Enol (2.486 m; Figura 12), generó un único arco morrénico que se 
corresponde con la parte frontal y la lateral derecha, cuya cota inferior se sitúa a 2.230 $\mathrm{m}$. Se trata de un depósito de escasa potencia, con pendientes suaves salvo en su parte externa, y caracterizado por la ausencia total de vegetación y suelos. Se aprecia con claridad el retoque nivoperiglaciar posterior, con abundantes cantos y bloques en posición planar, así como el derrubiado del depósito, especialmente en su porción exterior (González-Trueba, 2005). Sobre el sustrato rocoso ocupado por el glaciar es posible observar infinidad de estrías glaciares perfectamente conservadas, muy frescas. Por delante de la morrena de la PEH y a menor altitud también hay material morrénico, perteneciente en este caso al Tardiglaciar. En sus inmediaciones las estrías ya no se conservan y el pulido glaciar aparece retocado a escala de detalle por la karstificación superficial de la roca.

El frente del glaciar que se formó en la cara $\mathrm{N}$ de Peña Santa de Castilla durante la PEH estaba situado a $2.200 \mathrm{~m}$ de altitud. Se trata de un único arco morrénico de escasa potencia, carácter discontinuo y muy retocado por procesos postglaciares. Al interior del mismo, el sustrato calcáreo presenta huellas glaciares erosivas incontestables, estando repleto de estrías, especial- mente en un pequeño umbral situado bajo el nevero permanente más occidental de los dos que subsisten dentro área ocupada por el hielo glaciar en época histórica. Al igual que en los dos casos anteriores, el glaciar de la Forcadona, emplazado entre las cumbres de Peña Santa de Castilla al Este y las Torres del Torco al Oeste, edificó un único arco morrénico (Figura 14). El frente de este aparato se situó a $2.240 \mathrm{~m}$ de altitud. En la parte interna del complejo morrénico en los años en los que el nevero desaparece o queda muy mermado, es posible contemplar el hielo estratificado por debajo de la cubierta de derrubios que tapiza el fondo y las vertientes de la depresión en la que se instaló el glaciar (González-Trueba, 2005, 2007b). Sin embargo, este hielo carece de dinámica y se encuentra en clara regresión, con una temperatura muy próxima al punto de fusión, como se desprende de los registros térmicos obtenidos en los derrubios que lo recubren (Ruiz-Fernández et al., 2017). Se trata, por tanto, de un helero, el único que subsiste en el Macizo del Cornión como herencia del glaciarismo generado durante la PEH (González-Trueba, 2005). En el ámbito ocupado por los otros dos glaciares citados existen solamente neveros permanentes y semipermanentes. 


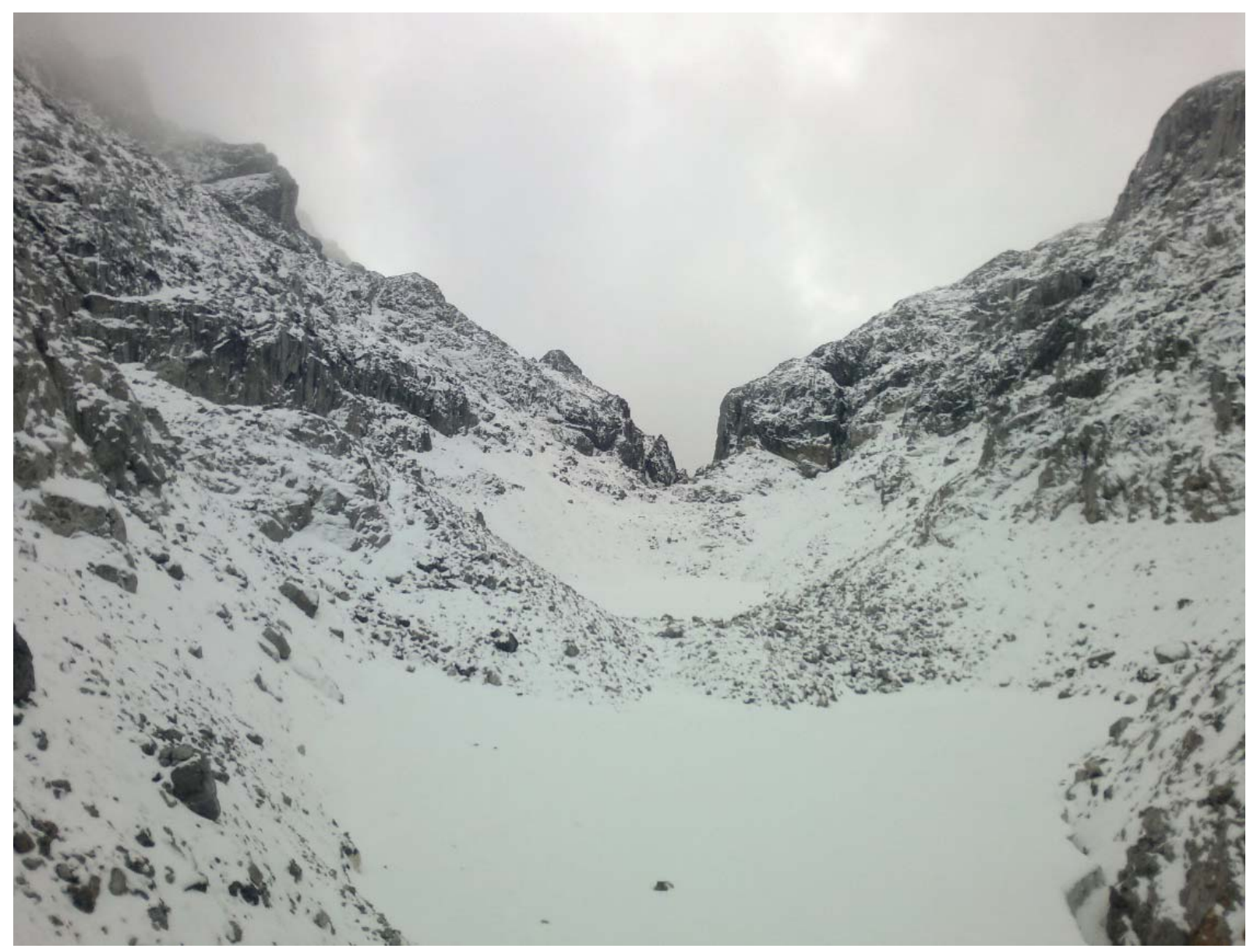

Fig. 14. Arco morrénico frontal parcialmente recubierto por la nieve, depositado por el glaciar de la PEH de la Forcadona.

En definitiva, estos tres glaciares de fondo de circo se desarrollaron durante el enfriamiento climático de la PEH, fase glaciar que en estas montañas ha tenido un carácter absolutamente marginal, en relación con unas condiciones límite que solamente permitieron la formación de masas de hielo en ámbitos con unos condicionantes topoclimáticos muy favorables (al pie de las cumbres más altas, en orientaciones Norte y por tanto a resguardo de la insolación, sobrealimentados por la caída de aludes, etc.) (González-Trueba, 2005, 2007b). En el Macizo Central de los Picos de Europa existieron otros tres glaciares durante la PEH (Jou Negro, Trasllambrión y la Palanca; González-Trueba, 2005, 2007a, 2007b;
González-Trueba et al., 2008). El resto de ámbitos montañosos ibéricos que estuvieron glaciados durante la PEH fueron los Pirineos, con 15 macizos y 111 circos con evidencias, y Sierra Nevada, con al menos dos glaciares en el interior de los circos del Mulhacén y el Veleta (Oliva et al., 2017).

\section{CONCLUSIONES}

Esta investigación estudia la morfología y la evolución glaciar del Macizo Occidental de los Picos de Europa, también conocido como Macizo del Cornión. A partir de los testimonios morfológicos que se conservan, así como de sus relaciones morfoestratigrá- 
ficas, han sido identificadas cuatro grandes fases glaciares. En la primera (Fase de Máxima Extensión del Hielo), el Cornión estuvo ocupado por ocho glaciares que conjuntamente ocuparon $7.329,8$ ha. Las dataciones obtenidas en el rellano de obturación glaciar de Belbín evidencian una cronología mínima de 36.718 \pm 1.203 años cal BP para dicha fase. Este resultado confirma una vez más la asincronía existente entre la máxima extensión local de los hielos en las Montañas Cantábricas y el UMGG. En la Fase Interna se desarrollaron también ocho glaciares, ocupando una superficie de 5.842,9 ha. A partir de la datación de la base de un sondeo de ocho metros procedente de la depresión del Bricial, se ha obtenido una edad mínima para esta segunda etapa de avance

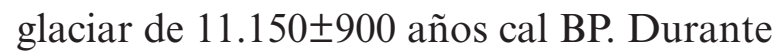
la Fase Glaciar de Altitud el Cornión contó con 37 pequeños glaciares (principalmente de circo) que tuvieron una extensión total de 797,4 ha. No contamos con datos cronológicos para esta fase, que tampoco ha sido datada directamente en otros macizos montañosos cantábricos, pese a estar ampliamente representada en muchos de ellos. Sin duda, ésta deberá ser una prioridad en los futuros estudios sobre el glaciarismo cantábrico. Finalmente, durante la $\mathrm{PEH}$ se formaron tres glaciares de circo al amparo de las cumbres más altas de macizo, con una extensión total de 10 ha. Como herencia de este glaciarismo histórico de carácter marginal, hoy en día aún subsiste un helero enterrado.

\section{AGRADECIMIEMTOS}

Este artículo ha sido financiado por el Ministerio de Economía, Industria y Competitividad del Gobierno de España (Ref. CTM2016-77878-P). Cristina García-Her- nández agradece el apoyo proporcionado por el programa FPU del Ministerio de Educación, Cultura y Deporte de España para el desarrollo de sus investigaciones.

\section{REFERENCIAS BIBLIOGRÁFICAS}

Carrasco, R.M., Pedraza, J., DomínguezVillar, D., Villa, J., Willenbring, J.K. (2013) The plateau glacier in the Sierra de Béjar (Iberian Central System) during its maximum extent. Reconstruction and chronology. Geomorphology, 196, 83-93.

Castañón, J.C. (1989) Las formas de relieve de origen glaciar en los sectores central y oriental del Macizo Asturiano. Universidad de Oviedo, Oviedo, 788 p. (microfichas).

Castañón, J.C. (1990) Datos para un estudio geomorfológico de la sierra de Cabezo Lloroso (Oriente de Asturias). Ería, 23, 258-264.

Castañón, J.C., Frochoso, M. (1998) La alta Montaña Cantábrica: condiciones térmicas y morfodinámicas en los Picos de Europa. En: Procesos biofísicos actuales en medios fríos, Gómez-Ortiz, A., Salvador, F., Schulte, L., García, A., Eds., Universidad de Barcelona, Barcelona, 113-132.

Delmas, M., Gunnell, Y., Braucher, R., Calvet, M., Bourlès, D. (2008) Exposure age chronology of the last glaciation in the Eastern Pyrenees. Quaternary Research, 69, 231-241.

Domínguez-Villar, D., Carrasco, R.M., Pedraza, J., Cheng, H., Edwards, R.L., Willenbring, J.K. (2013) Early maximum extent of paleoglaciers from Mediterranean mountains during the last glaciation. Scientific Reports, 3, 20-34. DOI: 10.1038/srep02034. 
Ehlers, J., Astakhov, V., Gibbard, P.L., Mangerud, J., Svendsen, J.I. (2006) Late Pleistocene Glaciations in Europe. En: Encyclopedia of Quaternary Science, Elias, S.A., Ed., Elsevier, Chichester, 10851095.

Flor, G., Bailón-Misioné, J.L. (1989) El glaciarismo cuaternario de los puertos de Áliva (Macizo Oriental de los Picos de Europa, occidente de Cantabria). Cuaternario y Geomorfología, 3 (1-4), 27-34.

Florineth, D., Schlüchter, C. (2000) Alpine evidence for atmospheric circulation patterns in Europe during the Last Glacial Maximum. Quaternary Research, 54, 295-308.

Frochoso, M. (1980). El Macizo Central de los Picos de Europa y sus glaciares. Ería, 1, 67-87.

Frochoso, M. (1990) Geomorfología del Valle del Nansa. Universidad de Cantabria, Santander, 281 p.

Frochoso, M., Castañón, J.C. (1986) La evolución morfológica del alto valle del Duje durante el Cuaternario (Picos de Europa, NW España). Ería, 11, 193-209.

Frochoso, M., Castañón, J.C. (1998) El relieve glaciar de la Cordillera Cantábrica. En: Las huellas glaciares de las montañas españolas, Gómez-Ortiz, A., Pérez-Alberti, A., Eds., Universidad de Santiago de Compostela, Santiago de Compostela, 65-137.

Frochoso, M., González, R., Allende, F. (2013) Pleistocene glacial morphology and timing of Last Glacial Cycle in Cantabrian Mountains (Northern Spain): new chronological data from the Asón Area. Central European Journal of Geoscience, 5, 12-27.

Gale, S.J., Hoare, P.G. (1997) The glacial history of the northwest Picos de Europa of northern Spain. Zeitschrift für Geomorphologie N. F., 41, 81-96.

Gallinar, D., Ruiz-Fernández, J., Poblete, M.A., Fernández, A., García, C., Beato, S., Marino, J.L. (2014) Morfología y evolución glaciar en el sector asturiano del Macizo de las Ubiñas. En: Avances de la Geomorfología en España 2012-2014, Schnabel, S., Gómez, A., Eds., Sociedad Española de Geomorfología, Cáceres, 543-546.

García de Celis, A. (1997) El relieve de la Montaña Occidental de León. Valladolid, Secretariado de Publicaciones de la Universidad de Valladolid, 290 p.

García-Ruiz, J.M., Martí, C., Peña, J.L., Sancho, C. Rhodes, E., Valero, B., González, P., Moreno, A. (2012) Glacial and fluvial deposits in the Aragón Valley, Central-Western Pyrenees: chronology of the Pyrenean Late Pleistocene glaciers. Geografiska Annaler, 95A, 15-32.

García-Ruiz, J.M., Moreno, A., González, P., Valero, B., Martí, C. (2010) La cronología del último ciclo glaciar en las montañas del Sur de Europa. Una revisión. Cuaternario y Geomorfología, 24 (1-2), 35-46.

García-Ruiz, J.M., Palacios, D., de Andrés, N., Valero, B.L., López, J.I., Sanjuán, Y. (2014) Holocene and 'Little ice age' glacial activity in the Marboré Cirque, Monte Perdido Massif, Central Spanish Pyrenees. The Holocene, 24 (11), 1439-1452.

García-Ruiz, J.M., Palacios, D., González, P., de Andrés, N., Moreno, A., Valero, B., Gómez, A. (2016) Mountain glacier evolution in the Iberian Peninsula during the Younger Dryas. Quaternary Science Reviews, 138, 16-30.

García-Ruiz, J.M., Valero, B., Martí, C., González, P. (2003) Asynchroneity of 
maximum glacier advances in the central Spanish Pyrenees. Journal of Quaternary Science, 18 (1), 61-72.

Gómez-Ortiz, A., Palacios, D., Palade, B., Vázquez, L., Salvador, F. (2012) The deglaciation of the Sierra Nevada (Southern Spain). Geomorphology, 159-160, 93-105.

González-Gutiérrez, R.B. (2002) El relieve de los valles del Torío y Curueño (Montaña Cantábrica Leonesa). Universidad de León, León, 267 p.

González-Sampériz, P., Valero, B.L., Moreno, A., Jalut, G., García-Ruiz, J.M., Martí, C., Delgado, A., Navas, A., Otto, T., Dedoubat, J.J. (2006) Climate variability in the Spanish Pyrenees during the last 30.000 yr revealed by the El Portalet sequence. Quaternary Research, 66, 38-52.

González-Trueba, J.J. (2005) La Pequeña Edad del Hielo en los Picos de Europa (Cordillera Cantábrica, NO de España). Análisis morfológico y reconstrucción del avance glaciar histórico. Cuaternario y Geomorfología, 19 (3-4), 79-94.

González-Trueba, J.J. (2007a) Geomorfología del Macizo Central del Parque Nacional Picos de Europa. OAPN, Ministerio de Medio Ambiente, Madrid, 231 p.

González-Trueba, J.J. (2007b) La Pequeña Edad del Hielo en los Picos de Europa. Servicio de Publicaciones de la Universidad de Cantabria - Fundación Marcelino Botín, Santander, 186 p.

González-Trueba, J.J., Martín, R., Martínez, E., Serrano, E. (2008) Little Ice Age glaciation and current glaciers in the Iberian Peninsula. The Holocene, 18 (4), 551-568.

González-Trueba, J.J., Serrano, E. (2011) El glaciarismo cuaternario en el Macizo del Cornión. En: Geomorfología del Macizo
Occidental del Parque Nacional Picos de Europa, González-Trueba, J.J. y Serrano, E., Eds., OAPN, Ministerio de Medio Ambiente, Madrid, 51-78.

Hughes, P.D., Woodward, J.C. (2008) Timing of glaciation in the Mediterranean mountains during the last cold stage. Journal of Quaternary Science, 23 (6-7), 575-588.

Hughes, P.D., Woodward, J.C., Gibbard, P.L. (2006) Quaternary glacial history of the Mediterranean mountains. Progress in Physical Geography, 30 (3), 334-364.

Ivy-Ochs, S., Kerschner, H., Reuther, A., Preusser, F., Heine, K., Maisch, M., Kubik, P.W., Schlüchter, C. (2008) Chronology of the last glacial cycle in the European Alps. Journal of Quaternary Science, 23, 559-573.

Jiménez, M. (1996) El glaciarismo en la cuenca alta del río Nalón: una propuesta de evolución de los sistemas glaciares cuaternarios en la Cordillera Cantábrica. Revista de la Sociedad Geológica de España, 9, 157-168.

Jiménez, M., Farias, P. (2002) New radiometric and geomorphologic evidences of a Last Glacial Maximum older than $18 \mathrm{ka}$ in SW European mountains: the example of Redes Natural Park (Cantabrian Mountains, NW Spain). Geodinamica Acta, 15, 93-101.

Jiménez, M., Rodríguez-Rodríguez, L., García-Ruiz, J.M., Domínguez, M.J., Farias, P., Valero, B., Moreno, A., Rico, M., Valcárcel, M. (2013) A review of glacial geomorphology and chronology in northern Spain: timing and regional variability during the last glacial cycle. Geomorphology, 196, 50-64.

Joly, F. (1997) Glossaire de géomorphologie. Base de données sémiologiques pour la 
cartographie. Armand Colin, París, 325 p.

Kuhlemann, J., Rohling, E., Krumrei, P., Ivy-Ochs, S., Kucera, M. (2008) Regional sintesis of Mediterranean atmospheric circulation during the Last Glacial Maximum. Science, 321, 1338-1340.

Martínez de Pisón, E., Arenillas, M. (1979) Algunos problemas de morfología glaciar en la España atlántica. Acta Geológica Hispánica, 14, 445-450.

Miotke, F.D. (1968) Karstmorphologische studien in der glazial-überformten Höhenstufe der Picos de Europa, Nordspanien. Selbtverlag der Geografischen Gessellschaft, Hannover, 161 p.

Moreno, A., Valero, B.L., Jiménez, M., Domínguez, M.J., Mata, M.P., Navas, A., González, P., Stoll, H., Farias, P., Morellon, M., Corella, J.P., Rico, M. (2010) The last deglaciation in the Picos de Europa National Park (Cantabrian Mountains, Northern Spain). Journal of Quaternary Science, 25 (7), 1076-1091.

Nieuwendam, A., Ruiz-Fernández, J., Oliva, M., Lopes, V., Cruces, A., Freitas, $M^{\mathrm{a}}$.C. (2016) Postglacial landscape changes and cryogenic processes in the Picos de Europa (Northern Spain) reconstructed from geomorphological mapping and microstructures on quartz grains. Permafrost and Periglacial Processes, 27, 96-108.

Oliva, M., Gómez, A., Palacios, D., Salvador, F., Salvà, M. (2014) Environmental evolution in Sierra Nevada (South Spain) since the last glaciation based on multi-proxy records. Quaternary International, 353, 195-209.

Oliva, M., Ruiz-Fernández, J., Barriendos, M., Benito, G., Cuadrat, M., DomínguezCastro, F., García-Ruiz, J.M., Giralt, S.,
Gómez-Ortiz, A. Hernández, A., LópezCostas, O., López-Moreno, J.I., LópezSáez, J.A., Martínez-Cortizas, A., Moreno, A., Prohom, M., Saz, M.A., Serrano, E., Tejedor, E., Trigo, R., Valero-Garcés, B., Vicente-Serrano, S.M. (2017) The Little Ice Age in Iberian mountains. Earth-Science Reviews, 177, 175-208.

Palacios, D., Andrés, N., Marcos, J., Vázquez, L. (2012a) Glacial landforms and their paleoclimatic significance in Sierra de Guadarrama, Central Iberian Peninsula. Geomorphology, 139-140, 67-78.

Palacios, D., Andrés, N., Marcos, J., Vázquez, L. (2012b) Maximum glacial advance and deglaciation of the Pinar Valley (Sierra de Gredos, Central Spain) and its significance in the Mediterranean context. Geomorphology, 177-178, 5161.

Palacios, D., Gómez, A., de Andrés, N., Vázquez, L., Salvador, F., Oliva, M. (2015) Maximum extent of late Pleistocene glaciers and last deglaciation of La Cerdanya mountains, Southeastern Pyrenees. Geomorphology, 231, 116-129.

Pallàs, R., Rodes, A., Braucher, R., Carcaillet, J., Ortuno, M., Bordonau, J., Bourles, D., Vilaplana, J.M., Masana, E., Santanach, P. (2006) Late Pleistocene and Holocene glaciation in the Pyrenees: a critical review and new evidence from $10 \mathrm{Be}$ exposure ages, south-central Pyrenees. Quaternary Science Reviews, 25, 2937-2963.

Pellitero, R. (2013) Evolución finicuaternaria del glaciarismo en el macizo de Fuentes Carrionas (Cordillera Cantábrica), propuesta cronológica y paleoambiental. Cuaternario y Geomorfología, (1-2), 71-90. 
Pérez-Alberti, A., Valcárcel, M., Martini, I.P., Pascucci, V., Andrucci, S. (2011) Upper Pleistocene glacial valley-junction sediments at Pias, Trevinca Mountains, NW Spain. En: Icemarginal and Periglacial Processes and Sediments, Martini, I.P., French, H.M., Perez-Alberti, A., Eds., Geological Society (London) Special Publication, 354, 93-110.

Rodríguez-Rodríguez, L., Jiménez, M., Domínguez, M.J., Aranburu, A. (2015) Research history on glacial geomorphology and geochronology of the Cantabrian Mountains, north Iberia (43-42 ${ }^{\circ} \mathrm{N} / 7-$ $\left.2^{\circ} \mathrm{W}\right)$. Quaternary International, 364, 6-21.

Rodríguez-Rodríguez, L. Jiménez, M., Domínguez, M.J., Rinterknecht, V., Pallàs, R., Bourlès, D. (2016) Chronology of glaciations in the Cantabrian Mountains (NW Iberia) during the Last Glacial Cycle based on in situ-produced 10Be. Quaternary Science Reviews, 138, 31-48.

Ruiz-Fernández, J. (2011) Geomorphological map of an Atlantic mid-height mountain area: the Juan Robre and Jana Ridge (Cantabrian Range, Northwest Spain). Journal of Maps, 7 (1), 260-272.

Ruiz-Fernández, J., Nieuwendam, A., Oliva, M., Lopes, V., Cruces, A., Freitas, M.C., Janeiro, A.I., López-Sáez, J.A. (2016a) Cryogenic processes and fire activity in a high Atlantic mountain area in NW Iberia (Picos de Europa) during the MidLate Holocene. Science of the Total Environment, 573, 1159-1170

Ruiz-Fernández, J., Oliva, M., Cruces, A., Lopes, V., Freitas, M.C., Andrade, C., García-Hernández, C., López-Sáez, J.A., Geraldes, M. (2016b) Environ- mental evolution in the Picos de Europa (Cantabrian Mountains, SW Europe) since the Last Glaciation. Quaternary Science Reviews, 138, 87-104.

Ruiz-Fernández, J., Oliva, M., Hrbáček, F., Vieira, G., García-Hernández, C. (2017) Soil temperatures in an Atlantic high mountain environment: The Forcadona buried ice patch (Picos de Europa, NW Spain). Catena, 149 (2), 637-647.

Ruiz-Fernández, J., Poblete, M.A., SerranoMuela, P., Martí-Bono, C., García-Ruiz, J.M. (2009) Morphometry of glacial cirques in the Cantabrian range (Northwest Spain). Zeitschrift für Geomorphologie N. F., 53, 47-68.

Ruiz-Fernández, J., Serrano, E. (2011) El modelado kárstico en el Macizo del Cornión. En: Geomorfología del Macizo Occidental del Parque Nacional Picos de Europa, González-Trueba, J.J. y Serrano, E., Eds., OAPN, Ministerio de Medio Ambiente, Madrid, 109-142.

Santos, J. (2010) Glaciarismo y periglaciarismo en el Alto Sil, Provincia de León (Cordillera Cantábrica). Tesis Doctoral (inédita), Departamento de Geografía y Geología de la Universidad de León, León, 689 p.

Santos, J., Redondo, J.M., González-Gutiérrez, R.B., Gómez-Villar, A. (2013) Applying the AABR method to reconstruct equilibrium-line altitudes from the last glacial maximum in the Cantabrian Mountains (SW Europe). Palaeogeography, Palaeoclimatology, Palaeoecology, 387, 185-199.

Serrano, E., González-Trueba, J.J. (2004) Morfodinámica periglaciar en el grupo Peña Vieja (Macizo Central de los Picos de Europa - Cantabria). Cuaternario y Geomorfología, 18 (3-4), 73-88. 
Serrano, E., González-Trueba, J.J., Serrano, E., González-Trueba, J.J., PellitGonzález-García, M. (2012) Mountain glaciation and paleoclimate reconstruction in the Picos de Europa (Iberian Peninsula, SW Europe). Quaternary Research, 78, 303-314. ero, R., González-García, M. y GómezLende, M. (2013) Quaternary glacial evolution in the Cantabrian Mountains (Northern Spain). Geomorphology, 196, 65-82. 